OPEN ACCESS

Edited by:

Bin Tang,

Hangzhou Normal University, China

Reviewed by:

Kai Lu,

Fujian Agriculture and Forestry

University, China

Haijian Huang,

Nanjing Agricultural University, China

*Correspondence:

Fang Liu

fangliu@yzu.edu.cn

${ }^{\dagger}$ These authors have contributed equally to this work

Specialty section:

This article was submitted to

Invertebrate Physiology,

a section of the journal

Frontiers in Physiology

Received: 02 July 2020

Accepted: 19 August 2020

Published: 16 September 2020

Citation:

Ge L, Jiang L, Zheng S, Zhou Y, Wu Q and Liu F (2020) Frizzled 2

Functions in the Regulation

of TOR-Mediated Embryonic

Development and Fecundity

in Cyrtorhinus lividipennis Reuter.

Front. Physiol. 11:579233.

doi: 10.3389/fphys.2020.579233

\section{Frizzled 2 Functions in the Regulation of TOR-Mediated Embryonic Development and Fecundity in Cyrtorhinus lividipennis Reuter}

\author{
Linquan Get, Lu Jiang ${ }^{\dagger}$, Sui Zheng, Yongkai Zhou, Qing Wu and Fang Liu* \\ School of Horticulture and Plant Protection, Yangzhou University, Yangzhou, China
}

The mirid bug, Cyrtorhinus lividipennis Reuter, is an important predator of rice planthoppers in Asia. In a previous study, C. lividipennis fed on gramineous weeds with brown planthopper (BPH) eggs had reduced development compared to those fed on rice with BPH eggs. In the current study, the concentrations of selected amino acids (AAs) were higher in rice than five gramineous species, which might explain the enhanced growth of $C$. lividipennis on rice. When $C$. lividipennis was fed on AA-deprived artificial diets, the Wnt/ $\beta$-catenin pathway was inhibited. Furthermore, C. lividipennis females silenced for expression of Frizzled 2 (Fz2) showed a significant reduction in the $\mathrm{Wnt} / \beta$-catenin and target of rapamycin (TOR) pathways. Silencing Fz2 led to decreased expression of the vitellogenin gene $(\mathrm{Vg})$, lower $\mathrm{Vg}$ accumulation in oocytes, reduced soluble protein in ovaries and fat bodies, reduced titers of juvenile hormone, prolonged preoviposition periods, and lower predation capacity, body weight, and egg numbers as controlled to controls. Fz2 silencing resulted in undeveloped ovaries and the inhibition of oocyte growth in the ovarioles, resulting in decreased numbers of offspring and reduced hatching rates. The silencing of $F z 2$ also resulted in aberrant embryos with undeveloped eyespots and organs, suggesting that Fz2 is an essential gene for embryonic development, oogenesis, and egg maturation. In summary, this study established a potential link between Wnt and TOR pathways, which interact synergistically to regulate $C$. lividipennis reproduction in response to AA signals. These results provide valuable new information that can be applied to large-scale rearing of $C$. lividipennis predators, which is important for reducing planthopper damage in rice fields.

Keywords: Cyrtorhinus lividipennis, Frizzled 2, target of rapamycin pathway, Wnt//-catenin pathway, fecundity

\section{INTRODUCTION}

The mirid bug, Cyrtorhinus lividipennis Reuter (Hemiptera: Miridae), is prevalent in rice fields and is an important predator of leafhoppers and planthoppers, including the brown planthopper (BPH), Nilaparvata lugens Stål (Hemiptera: Delphacidae). C. lividipennis feeds on planthopper eggs and nymphs in irrigated rice fields (Katti et al., 2007; Sigsgaard, 2007). Predacious C. lividipennis 
nymphs can consume approximately 7.5 eggs or 1.4 nymphs per day over a 2-week period, and adults can consume 10 eggs, 4.7 nymphs, or 2.4 adults per day over a 10-day period (Reyes and Gabriel, 1975); thus, a single bug can consume up to 66 nymphs during its 24-day life span. Previously, C. lividipennis was shown to feed on $\mathrm{BPH}$ eggs inhabiting different gramineous species growing in the perimeter of rice fields; however, longevity, development, and reproduction were reduced on gramineous species when compared to rice plants (Yu et al., 1996). One possible explanation for this finding is that rice is more nutrient dense than the surrounding gramineous species, and the enriched nutritional content of rice might promote greater survival and development of C. lividipennis in comparison to gramineous weeds. One transducer of nutritional signals is the target of rapamycin (TOR) pathway, which transmits amino acid (AA) signals (Fingar and Blenis, 2004; Attardo et al., 2006; Loewith and Hall, 2011) and regulates vitellogenesis via the $V g$ gene (Hansen et al., 2004, 2005). When TOR was inhibited by rapamycin or RNAi, $V g$ expression and egg production were inhibited in the mosquito, Aedes aegypti (Hansen et al., 2005). The AAdependent TOR signaling pathway was shown to mediate the phosphorylation of S6K kinase (Hansen et al., 2005), which is a critical regulator of $V g$ expression (Attardo et al., 2003; Park et al., 2006).

Wnt1, which was originally named Int-1, was first identified in mouse cancer cells (Nusse and Varmus, 1982). In a subsequent report, a homolog of Wnt named Wingless was identified in Drosophila (Rijsewijk et al., 1987) and was shown to function in fly development as part of a developmental cascade (Vinson et al., 1989; Clevers, 2006). The glycoprotein Wnt and Frizzled $(\mathrm{Fz})$, a transmembrane receptor for Wnt, interact at the cell surface as part of a signal transduction pathway that regulates gene expression (Logan and Nusse, 2004; Sen and Ghosh, 2008). In canonical Wnt signaling pathways, Wnt ligands bind to Frizzled/low-density lipoprotein receptorrelated protein (LRP), which activates Dvl (scaffold protein) and results in the inactivation of glycogen synthase kinase 3 (GSK3 $\beta$ ) and stabilization of the cytosolic co-activator protein, $\beta$-catenin (Clevers, 2006). The accumulation of $\beta$-catenin in the cytosol leads to translocation into the nucleus, thus causing the formation of the transcriptionally activated TCF ( $\mathrm{T}$ cell factor) complex at the promoter regions of target genes (Clevers, 2006). In contrast, non-canonical Wnt signaling depends on intermediary proteins, such as calmodulin kinase (CamK) and protein kinase $\mathrm{C}(\mathrm{PKC})$, which do not require $\beta$-catenin (Logan and Nusse, 2004; Gordon and Nusse, 2006; Mikels and Nusse, 2006; Sen and Ghosh, 2008; Mosimann et al., 2009). Drosophila Fz2 was previously shown to modulate embryonic patterning (Kennerdell and Carthew, 1998). In the mosquito Anopheles gambiae, which vectors the malarial parasite Plasmodium berghei, Fz2 triggered melanization in the mosquito midgut after infection with $P$. berghei (Shiao et al., 2006). More recently, Fz2 was shown to function with the TOR pathway in egg production by the mosquito Aedes aegypti (Weng and Shiao, 2015).

Although multiple intermediary proteins have been identified in the Wnt signaling pathway (Behura et al., 2011), the function of $\mathrm{Fz} 2$ in transducing $\mathrm{AA}$ signals in C. lividipennis is unknown. In this study, we investigate the involvement of $\mathrm{Wnt} / \beta$-catenin and TOR pathways in response to AAs signals in $C$. lividipennis and their potential role in reproduction. Our results may eventually result in an optimized artificial diet for large-scale rearing of C. lividipennis, which would improve our ability to deploy the predator for $\mathrm{BPH}$ control in rice fields.

\section{MATERIALS AND METHODS}

\section{Measurement of Amino Acid Concentrations}

Stems (0.1 g fresh weight) were removed from rice (40 days) and five gramineous (40 days) species (Digitaria ciliaris, Cynodon dactylon, Leptochloa chinensis, Elusine indica, and Echinochloa glabrescens) and transferred to $1 \mathrm{ml}$ of $6 \mathrm{~mol} / \mathrm{L}$ $\mathrm{HCl}$ for $15 \mathrm{~min}$. Suspensions were allowed to settle for $15 \mathrm{~min}$ at room temperature, and an aliquot $(0.5 \mathrm{ml})$ was centrifuged at $10,000 \times \mathrm{g}$ to produce a clear extract. AAs were extracted using the EZ:Fast Free Amino Acid kit (Phenomenex, CA, Unitd States). Gas chromatography (GC)mass spectrometry (MS) analysis of the extracted samples was conducted as described (Curtis et al., 2016). AA standards were supplied with the EZ:Fast kit, and calibration curves were calculated for each AA. Data were analyzed with Agilent 5975 software.

\section{Insect Rearing}

C. lividipennis was collected from rice fields located at Yangzhou University, Yangzhou, China. Mirid bug colonies were reared in a controlled environmental chamber maintained at $26 \pm 2{ }^{\circ} \mathrm{C}$ and $75 \%$ relative humidity $(\mathrm{RH})$ with a 16:8 h light:dark photoperiod for multiple generations. C. lividipennis were supplied with $\mathrm{BPH}$ eggs as a food source.

\section{Quantitative Real-Time PCR}

Total RNA was isolated from C. lividipennis with Trizol reagent (Invitrogen, Carlsbad, CA, United States) and treated with RNase-free DNase I. cDNA was synthesized using PrimeScript RT Reagent Kit with gDNA Eraser (TakaRa Beijing, China) in 20 $\mu l$ reaction mixtures containing random hexamers and oligo $\mathrm{dT}$ primers at $37^{\circ} \mathrm{C}$ for $15 \mathrm{~min}$.

Quantitative real-time PCR (qPCR) was carried out using a CFX Touch Real-Time PCR system (Bio-Rad, California, United States) in 96-well plates with the SYBR Premix EX Taq Kit (TaKaRa, Beijing, China). Each qPCR reaction contained SYBR master mix $(5 \mu \mathrm{l})$, cDNA template $(1 \mu \mathrm{l})$, primers $(0.4$ $\mu \mathrm{l} /$ per primer at $10 \mu \mathrm{mol})$, and $\mathrm{ddH}_{2} \mathrm{O}(3.2 \mu \mathrm{l})$. Reaction conditions were as follows: $95^{\circ} \mathrm{C}$ for $30 \mathrm{~s}, 35$ cycles at $95^{\circ} \mathrm{C}$ for $5 \mathrm{~s}, 58^{\circ} \mathrm{C}$ for $15 \mathrm{~s}$, and $72^{\circ} \mathrm{C}$ for $30 \mathrm{~s}$. Reactions were normalized using $\beta$-actin, and relative mRNA expression levels were obtained using the $2^{-\Delta \Delta c t}$ method (Livak and Schmittgen, 2001). The primers used for qPCR are shown in Supplementary Table S2. 


\section{Expression in Different Developmental Stages}

$F z 2$ expression in C. lividipennis was estimated by $\mathrm{qPCR}$ as described above using primers QFz2-F and QFz2-R (Supplementary Table S2). Total RNA was isolated from eggs $(n=50, N=3)$, first to fifth instar larvae $(n=10, N=3)$ and 1- and 2-day-old female adults $(n=5, N=3)$. Reactions were conducted in a final volume of $10 \mu \mathrm{l}$ containing $1 \mu \mathrm{l}$ of the cDNA sample (or standard), $0.2 \mu \mathrm{l}(10 \mathrm{pmol} / \mu \mathrm{l})$ of each primer and $5 \mu \mathrm{l}$ SYBR premix Ex Taq. $\beta$-actin was amplified from C. lividipennis with actin-F and actin-R primers (Supplementary Table S2) and used as an internal control. Standard curves were constructed with 10-fold serial dilutions of cDNA from a pool of 30 individuals as described previously (Chen et al., 2010). Relative mRNA expression was calculated as the means of three individual measurements \pm SEM.

\section{Expression in Different Tissues}

To evaluate $F z 2$ expression in different tissues, total RNA was extracted from the heads $(n=20, N=3)$, fat bodies $(n=15$, $N=3)$, midguts $(n=30, N=3)$, ovaries $(n=15, N=3)$, cuticula $(n=30, N=3)$, and legs $(n=30, N=3)$. One or two organs/mirid bug were collected, rinsed in phosphate buffer saline (PBS), and combined with organs from 15-30 individuals as described (Chen et al., 2010). PCR was conducted in a final volume of $20 \mu \mathrm{l}$ using the reagents, primers, and conditions described above. PCR products $(5 \mu \mathrm{l})$ were separated by electrophoresis, and gels were stained with ethidium bromide as described previously (Chen et al., 2010).

\section{Artificial Diets of C. lividipennis}

Artificial diets of $C$. lividipennis were prepared according to Supplementary Table S3. Compounds were dissolved in $\mathrm{ddH}_{2} \mathrm{O}$, and the $\mathrm{pH}$ was adjusted to 6.4 with $4 \% \mathrm{KOH}$ in a total volume of $100 \mathrm{ml}$. Diets were prepared with AAs (normal artificial diet, including six AAs), lacking multiple AAs (-6 AAs, -Arg, -Lys, -Ser, -Pro, -Ala, and -Thr) or lacking individual AAs (-1 AA, -Arg, -Lys, -Ser, -Pro, -Ala, or -Thr). Glass cylinders ( $7.5 \mathrm{~cm} \times 1.2$ $\mathrm{cm}$ ) were used as feeding chambers. A $50 \mu \mathrm{l}$ aliquot of the artificial diet was contained between two layers of a Parafilm membrane at the open end of the chamber (the diet capsule), and sterile absorbent cotton was placed at the bottom of the glass cylinder. The diet capsule was replaced every other day,

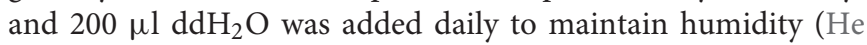
et al., 2014). Cylinders were covered with a black cotton cloth, and the open end containing the diet capsule was exposed to light. C. lividipennis (10 first instar individuals) was allowed to feed on the diet capsule by puncturing the inner Parafilm membrane, and a total of 10 chambers were used to rear nymphs for each treatment. Rearing was conducted in growth chambers maintained at $26 \pm 2^{\circ} \mathrm{C}, 80 \% \mathrm{RH}$ with a $16: 8 \mathrm{~h}$ light:dark photoperiod. Mortality was recorded every other day.

\section{Synthesis of DsRNA and Microinjection}

For dsRNA synthesis, a 388 bp fragment of $F z 2$ was amplified from cDNA using forward and reverse primers Fz2-F and Fz2-R, respectively (Supplementary Table S2). The reaction conditions were as follows: 35 cycles at $95^{\circ} \mathrm{C}$ for $30 \mathrm{~s}, 58^{\circ} \mathrm{C}$ for $30 \mathrm{~s}$, and $72^{\circ} \mathrm{C}$ for $45 \mathrm{~s}$, with a final extension at $72^{\circ} \mathrm{C}$ for $10 \mathrm{~min}$. PCR products were sequenced, and only products where forward and reverse sequences aligned well (98\%) were used as templates for dsRNA synthesis. The gene-encoding green fluorescent protein (GFP) from Expression vector PHT3AG (ACY56286) was used as control dsRNA, and primers GFP-F and GFP-R were used to amplify the $688 \mathrm{bp}$ fragment containing GFP from Expression vector PHAT3AG plasmid. The T7 RiboMax Express RNAi System (Promega, Madison, WI, United States) was used to prepare dsRNAs. Sense and antisense dsRNAs were generated in separate reactions, precipitated and resuspended in nuclease-free water as described previously (Chen et al., 2010). The quantity and purity of dsRNAs were determined by UV spectroscopy and agarose gel electrophoresis.

C. lividipennis was microinjected with dsRNA as described by Wang et al. (2018). In a preliminary study, we evaluated five different dsRNA concentrations, which were designated high (80 and $100 \mathrm{ng}$ ), medium (40 and $60 \mathrm{ng}$ ), and low (20 ng); $60 \mathrm{ng}$ dsFz2 was selected as an optimum concentration based on the survival rate and RNAi efficiency of C. lividipennis (data not shown). Purified dsFz2 (60 ng) was injected into the mesothorax of fifth instar C. lividipennis nymphs using a FemtoJet Microinjector (Eppendorf-Nethler-Hinz, Hamburg, Germany); nymphs were then transferred into glass cylinders $(7.5 \times 1.2 \mathrm{~cm})$ that served as feeding chambers. Diet capsules were replenished every other day. Newly emerged, dsFz2-treated virgin females were then paired with an untreated male. Adult females $(n=100)$ were collected 2 days after emergence (DAE) to determine soluble protein content of ovaries and fat bodies ( $n=15, N=3$ replicates), juvenile hormone $(\mathrm{JH}) \mathrm{III}$ and ecdysteroid titers (entire body of mated female, $n=5, N=3$ ), and body weight ( $n=10, N=3$ ). Furthermore, the expression of $\mathrm{Wnt} / \beta$-catenin signaling genes (Wnt, Dvl, GSK3 $\beta, \beta$-catenin, and TCF) was examined, and the number of developed oocytes at $4 \mathrm{DAE}(n=10)$ was assessed. Fat bodies were examined to determine the accumulation of $\mathrm{Vg}$ mRNA and protein at 2 DAE. Fifty dsFz2-treated, mated adult females were collected at $1,2,3,5$, and 7 DAE to examine the efficiency of silencing by RNAi $(n=5, N=3)$. Fifty dsFz2-treated, mated adult females were also dissected to obtain reproductive tracts at 4 DAE (Ge et al., 2020). The longevity of adult females, preoviposition and oviposition periods, and number of eggs laid per mating pair were determined (one dsFz2-treated female mated with an untreated male; and one dsGFP-treated female mated with an untreated male; $n=10$ ). The number of eggs laid by the following pairs was also determined: one dsFz2-treated female mated with an untreated control male, one dsTOR-treated $(50 \mathrm{ng})$ female mated with an untreated male, one dsTOR/dsFz2treated female mated with an untreated male, and one dsGFPtreated female mated with an untreated male $(n=10)$.

\section{Protein Extraction and Determination}

Soluble proteins were extracted from fat bodies and ovaries of 50 dsFz2- and 50 dsGFP-treated mated females using a method similar to that described previously (Ge et al., 2010). Briefly, individual tissues were dissected from adult females 
at $2 \mathrm{DAE}$, transferred to microcentrifuge tubes $(1.5 \mathrm{ml})$ and weighed. A $600 \mu \mathrm{l}$ solution of a $\mathrm{NaCl}$ solution $[0.4 \mathrm{M} \mathrm{NaCl}$, $1 \mathrm{M}$ phenylmethylsulfonyl fluoride (PMSF)] was added, and tissues were homogenized and centrifuged as described (Ge et al., 2010). The upper lipid layer was filtered with glass fibers, $\mathrm{dd}_{2} \mathrm{O}$ was added, stored at $4^{\circ} \mathrm{C}$ overnight, and centrifuged at $4,000 \times \mathrm{g}$ at $4^{\circ} \mathrm{C}$ for $10 \mathrm{~min}$ (Ge et al., 2010). Supernatants were removed, and protein sediments were dissolved in $1.0 \mathrm{ml}$ of cold $0.4 \mathrm{M} \mathrm{NaCl}$.

Protein concentrations were determined using the Bradford, 1976 method (1976) and Coomassie Brilliant Blue R250 (Shanghai Chemical Agent Co., Ltd., Shanghai, China). $A_{595}$ values were measured by UV spectroscopy, and protein concentrations were determined with a standard curve of bovine serum albumin (BSA) (Shanghai Biochemistry Research Institute, Shanghai, China). Treatments and controls consisted of three independent biological replicates.

\section{Measurement of $\mathrm{JH}$ III and Ecdysteroid Titers}

JH III and ecdysteroid titers in mated adult females at 2 DAE were measured by high-performance liquid chromatography (HPLC)/MS (Cornette et al., 2008; Giebbultowicz et al., 2008). JH III and 20-hydroxyecdysone standards were obtained from Sigma-Aldrich (Sigma, United States). Treatments and controls were replicated three times.

\section{Female Body Mass and Isolation of Ovaries}

The weight of $10 \mathrm{dsFz2}$ - and 10 dsGFP-treated mated females were recorded at 2 DAE (Mettler-Toledo EC 100; $0.0001 \mathrm{~g}$ sensitivity). Treatments and controls consisted of three independent biological replicates $(n=10, N=3)$. Ovaries ( $n \geq 10$ mated females from dsFz2 and dsGFP treatments at $2 \mathrm{DAE}, N=3$ ) were isolated in $0.01 \mathrm{M} \mathrm{PBS}$, fixed in $3.8 \%$ formaldehyde, and washed with $0.2 \%$ Triton $\mathrm{X}-100$ as described previously (Ge et al., 2019). Images were captured with a Leica DMR connected to a Fuji Fine PixS2 Pro digital camera (Germany).

\section{Methoprene Treatment}

A stock solution $(100 \mu \mathrm{g} / \mu \mathrm{l})$ of the $\mathrm{JH}$ analog (JHA) methoprene (Sigma) was prepared in acetone as described (Ge et al., 2020) and diluted to $10 \mu \mathrm{g} / \mu \mathrm{l}$ in acetone and $\mathrm{ddH}_{2} \mathrm{O}$ (1:9 $\mathrm{v} / \mathrm{v})$. Newly emerged females that had been microinjected with dsFz2 as fifth instar nymphs were selected, and a 1 $\mu l$ aliquot of the diluted solution was applied topically as described previously (Ge et al., 2020). Treated C. lividipennis females were transferred into glass cylinders and maintained on normal artificial diets. Mated, dsFz2-treated C. lividipennis females were collected at $2 \mathrm{DAE}$ following the topical application of methoprene, and the expression levels of Rheb, TOR, S6K, and $V g$ were determined by qPCR. Phosphorylation of S6K and synthesis of $\mathrm{Vg}$ protein were determined by Western blot (WB) analysis. Treatments and controls consisted of three independent biological replicates.

\section{Western Blot Analysis}

Isolated fat bodies of dsFz2-treated C. lividipennis were homogenized in $0.5 \mathrm{ml}$ ice-cold lysis buffer that was supplemented with protease and phosphatase inhibitors as described ( $\mathrm{Lu}$ et al., 2016). After incubation for $1 \mathrm{~h}$ at $4^{\circ} \mathrm{C}$, lysates were centrifuged and $30 \mu \mathrm{g}$ total protein was separated by $10 \%$ sodium dodecyl sulfate (SDS)-polyacrylamide gel electrophoresis (PAGE) and transferred to polyvinylidene fluoride (PVDF) membranes; these were treated with blocking buffer and then incubated with primary antibodies as described (Lu et al., 2016). Anti-phospho-p70 S6 kinase (p70-Thr-389 S6K) polyclonal antisera were obtained from Cell Signaling Technology (Danvers, MA, United States), and anti-Vg antisera were prepared by Nanjing Kingsley Biotechnology Co., Ltd. (Nanjing, China). Antisera to $\beta$-actin were used as a loading control. After membranes were washed with TBST (Tris-buffered saline, $\mathrm{pH} 7.4,0.5 \%$ Tween-20), they were incubated in blocking buffer with goat anti-rabbit immunoglobulin G (IgG)-conjugated to horseradish peroxidase secondary antibodies (Sigma) for $1 \mathrm{~h}$ at room temperature. Bands were visualized with chemiluminescent substrates and photographed with the GBOX-Chemi XT4 (Syngene, Cambridge, United Kingdom) as described previously (Lu et al., 2016).

\section{Immunohistochemical Staining}

Ovaries from C. lividipennis dsFz2- or dsGFP- treated fifth instar nymphs were removed at $4 \mathrm{DAE}$ and fixed in PBS containing 20\% surcose and 4\% paraformaldehyde (Zhang et al., 2015). Ovaries were washed three times in PBS containing $0.1 \%$ Triton X-100 (PBST), blocked in PBST containing 10\% fetal bovine serum, and incubated with anti-Vg (1:500) as described previously (Ge et al., 2020). Samples were rinsed three times in PBS ( $5 \mathrm{~min} /$ wash), and a 1:500 dilution of Alexa Fluor 488-labeled goat anti-rabbit antisera (Abbkine, Redlands, CA, United States) was added (Zhang et al., 2015). After a $1 \mathrm{~h}$ incubation at ambient temperature, nuclei were counterstained with $100 \mathrm{nM} \mathrm{4}$ ',6-diamidino-2-phenylindole (DAPI) (Beyotime, Shanghai, China) in PBST for $10 \mathrm{~min}$ at room temperature. Samples were mounted on glass slides and washed in PBS $(3 \times, 5 \mathrm{~min})$. Fluorescence images were captured with a Zeiss LSM 780 confocal microscope (Carl Zeiss MicroImaging, Göttingen, Germany).

\section{Predation Capacity of C. lividipennis}

The predation capacity of $C$. lividipennis was measured as described by Base et al. (2002) with minor modifications. First instar nymphs of $\mathrm{BPH}(n=20)$ were placed in glass tubes ( 3 $\mathrm{cm} \times 25 \mathrm{~cm})$ containing four 15-day-old rice seedlings of rice $\mathrm{cv}$. Ningjin 4, which is susceptible to BPH. Newly emerged $(<24$ h) C. lividipennis adult females were individually placed into glass tubes, which were then sealed with nylon mesh. Surviving $\mathrm{BPH}$ nymphs were recorded daily, and the predation number per C. lividipennis was accessed based on survival counts of $\mathrm{BPH}$ nymphs at days 1 and 3. Treatments and controls consisted of five independent biological replicates. 


\section{Population Growth}

Two groups were established to monitor population growth: dsGFP-treated females mated with untreated males (control group), and dsFz2-treated females mated with untreated males (treatment group). A randomized complete block containing five replicates was used as an experimental design. Newly emerged C. lividipennis (two pairs) were released on rice plants containing $N$. lugens eggs at the tillering stage (40 days) and enclosed in nylon cylindrical cages as described (Ge et al., 2017). When third instar nymphs of the next generation emerged (approximately 25 days), groups were inspected daily and third instar nymphs were counted; these were transferred to new plastic pots with growing rice plants. Nymphs were examined every 2 days until adults emerged; numbers of both sexes were recorded until the females died. Numbers of adults from the new generation and unhatched egg counts were used to calculate hatch rates and the ratio of adults/adults + unhatched eggs (Ge et al., 2017). The population growth index (PGI) was calculated as described (Ge et al., 2017).

\section{Statistical Analysis}

Normal distributions and homogeneity of variances were confirmed prior to ANOVA as described (Ge et al., 2017). A oneway ANOVA was conducted for soluble proteins (ovaries and fat bodies), body weight, JH III and ecdysone titers, longevity, preoviposition and oviposition periods, number of developed oocytes, numbers of eggs laid and offspring, hatching rate, gender ratio, and mRNA expression levels. Unless otherwise noted, data are expressed as means \pm standard error (SEM) from three independent biological replicates. Two-way (days after emergence and dsRNA treatment) ANOVAs were used to analyze the data. Multiple comparisons of the means were calculated with Fisher's protected least significant difference test. All analyses were conducted using the data processing system of Tang and Feng (2007).

\section{RESULTS}

\section{Amino Acid Concentrations in Rice and Gramineous Species}

The free AA content of five gramineous species (D. ciliaris, C. dactylon, L. chinensis, E. indica, and E. glabrescens) and rice were analyzed and compared (Supplementary Table S1). The concentrations of Ala, Lys, Pro, Arg, Ser, and Thr were significantly higher in rice than in the five gramineous species; an exception was the higher Lys content in E. glabrescens as compared to rice (Supplementary Table S1).

\section{Frizzled 2 Expression Levels in C. lividipennis}

With respect to developmental stages, $F z 2$ expression increased in fifth instar nymphs and adult $C$. lividipennis $(F=213.8 ; \mathrm{df}=7$, 23; $P=0.0001$ ) and was $49 \sim 132 \%$ higher than that in egg (Figure 1A). Fz2 was highly expressed (7-fold higher) in the fat body of $C$. lividipennis female adults at $2 \mathrm{DAE}(F=212.2 ; \mathrm{df}=5$,
17; $P=0.0001)$ (Figure 1B). In C. lividipennis females treated with $60 \mathrm{ng} \mathrm{dsFz2}$, expression of $F z 2$ was $69 \sim 84 \%$ lower than that in dsGFP-treated females at 1, 2, 3, 5, and 7 DAE (Figure 1C).

\section{Amino Acid Signals Mediate Transcriptional Changes in the Wnt/ $\beta$-Catenin Pathway}

The expression of Wnt pathway genes (Wnt, Fz2, Dvl, GSK3 $\beta, \beta$ catenin, and TCF) was monitored in C. lividipennis females fed on artificial diets lacking one or more AAs (Figure 2). There were no significant differences in Wnt expression in C. lividipennis fed on various artificial diets $(F=0.9 ; \mathrm{df}=7,23 ; P=0.4901)$ (Figure 2A). However, $F z 2$ was differentially expressed in C. lividipennis fed on diets lacking one or more AAs (Figure 2B). A significant reduction in expression was observed for insects fed on diets lacking all six AAs $(\downarrow 56 \%)$ or lacking $\operatorname{Arg}(\downarrow 32 \%)$, Ser, $(\downarrow 40 \%)$, Pro $(\downarrow 33 \%)$, or Ala $(\downarrow 37 \%)(F=24.7$; df $=7,23 ; P=0.0001)$. No significant differences were noted for $F z 2$ expression on diets lacking Lys or Thr. The expression of $D v l$ showed a $45 \%$ decrease when insects were fed on diets lacking all six AAs; reductions were $\downarrow 38 \%$ for diets lacking Arg (-Arg), $\downarrow 36 \%$ for -Lys, $\downarrow 41 \%$ for -Ser, $\downarrow 29 \%$ for Pro, and $\downarrow 28 \%$ for Ala $(F=10.7$; df $=7,23$; $P=0.0001)$. $D v l$ expression level was not significantly altered in diets lacking Thr (Figure 2C). Expression levels of GSK3 $\beta$ were upregulated in diets lacking the six AAs and in diets lacking Arg, Lys, Ser, and Ala. GSK3 $\beta$ expression was downregulated in diets lacking Thr and was not significantly altered in diets lacking Pro (Figure 2D). $\beta$-catenin showed significant decreases in expression (Figure 2E) when one or more AAs were absent; e.g., $\downarrow 29 \%$ for diets lacking all six AAs, $\downarrow 23 \%$ for diets lacking Arg (Arg-), $\downarrow 25 \%$ for Lys-, $\downarrow 26 \%$ for Ser-, $\downarrow 32 \%$ for Pro-, $\downarrow 31 \%$ for Thr-, and $\downarrow 22 \%$ for Ala- $(F=7.7$; $\mathrm{df}=7,23 ; P=0.0004)$. TCF expression was reduced in insects fed on diets lacking the six AAs $(\downarrow 27 \%)$ and in diets lacking Arg ( $\downarrow 32 \%)$, Lys $(\downarrow 20 \%)$, Ser $(\downarrow 35 \%)$, and Ala $(\downarrow 21 \%)(F=36.5 ; \mathrm{df}=7,23 ; P=0.0001)$ (Figure 2F).

\section{Silencing Frizzled 2 Inhibits Wnt and Target of Rapamycin Pathways}

The expression of selected Wnt pathway genes was analyzed in C. lividipennis females treated with dsFz2 or dsGFP. No significant differences were observed in Wnt transcription levels in dsFz2- and dsGFP-treated insects (Figure 3A). However, C. lividipennis treated with dsFz2 showed a significant reduction in the expression of $F z 2$ (Figure 3B; $\downarrow 82 \%: F=595.1 ; \mathrm{df}=1,5$; $P=0.0001), D v l$ (Figure 3C; $\downarrow 59 \%: F=42.0 ; \mathrm{df}=1,5 ; P=0.0029)$, $\beta$-catenin (Figure 3E; $\downarrow 37 \%: F=18.7$; $\mathrm{df}=1,5 ; P=0.0001$ ), and TCF (Figure 3F; $\downarrow 32 \%: F=15.6 ; \mathrm{df}=1,5 ; P=0.0167$ ) relative to dsGFP treatments at 2 DAE. Interestingly, dsFz2treated C. lividipennis showed significant upregulated levels of GSK3 $\beta$ (Figure 3D; $\uparrow 73 \%: F=274.1 ; \mathrm{df}=1,5 ; P=0.0001$ ) relative to dsGFP-treated controls.

C. lividipennis females treated with dsFz2 also showed reduced transcription of Rheb $(F=49.4 ; \mathrm{df}=1,5 ; P=0.0001)$, TOR $(F=30.9 ; \mathrm{df}=1,5 ; P=0.0051)$, and $S 6 k(F=30.3 ; \mathrm{df}=1$, 5; $P=0.0001$ ), which were 56,44 , and $49 \%$ lower than dsGFPtreated C. lividipennis at $2 \mathrm{DAE}$, respectively (Figures $\mathbf{4 A}-\mathrm{C}$ ). 
A

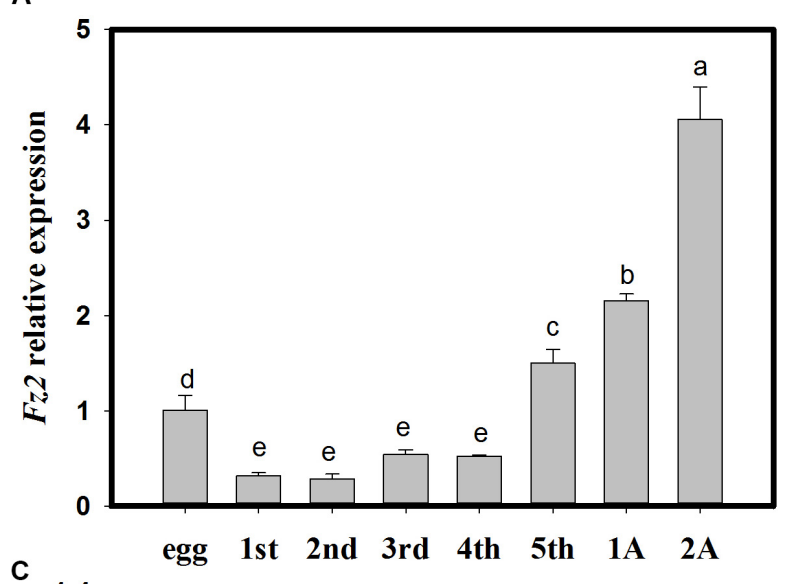

C

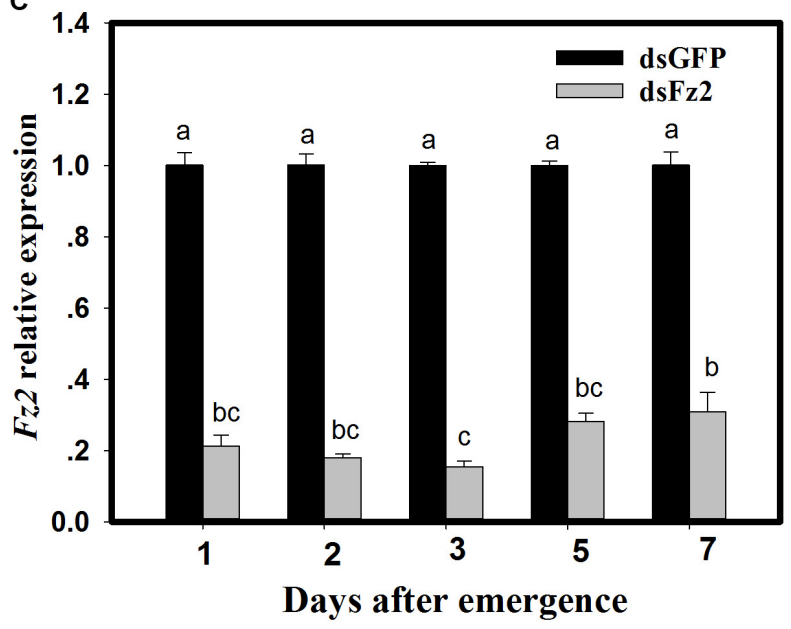

B

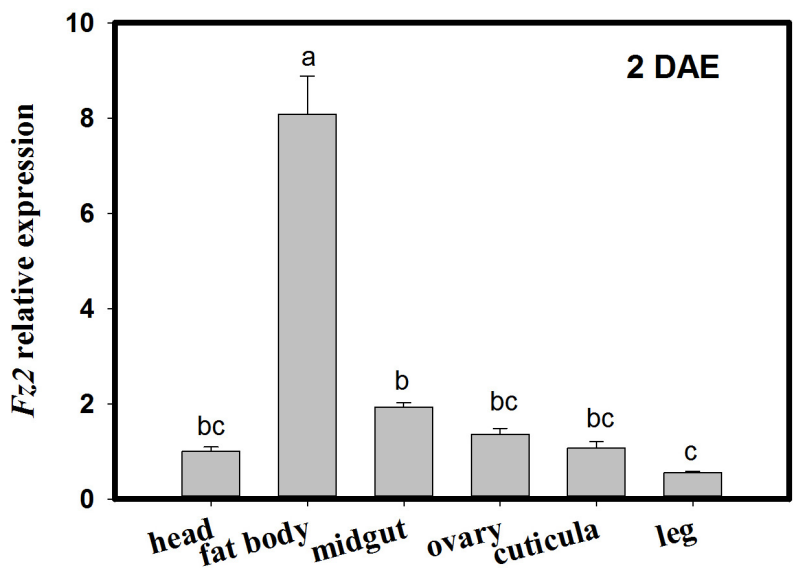

FIGURE 1 | Frizzled 2 (Fz2) expression profiles and RNAi silencing efficiency in Cyrtorhinus lividipennis females. Panels show the mean expression of Fz2 at different development stages (A) and in different tissues (B). (C) Shows Fz2 expression in dsFz2- and dsGFP-treated C. lividipennis females at different days after emergence (DAE), which is an indicator of RNAi-mediated silencing efficiency. The data are from three independent biological replicates and are presented as mean \pm SEM.

Western blot analysis confirmed that the fat bodies in dsFz2treated C. lividipennis females had lower levels $(\sim 41 \%)$ of S6K phosphorylation than dsGFP-treated insects (Figure 4D). Thus, $F z 2$ silencing results in significant inhibition of selected genes in the $\mathrm{Wnt} / \beta$-catenin and TOR pathways.

\section{Frizzled 2 Silencing Inhibits Vg Expression}

C. lividipennis females treated with dsFz2 exhibited $\sim 64 \%$ lower $V g$ expression as compared to dsGFP-treated females at $2 \mathrm{DAE}$ (Figure 5A; $F=184.7 ; \mathrm{df}=1,5 ; P=0.0001$ ). As expected, dsFz2mediated silencing also depleted the amount of $\mathrm{Vg}$ in the fat body of C. lividipennis female adults, which was approximately $42 \%$ lower than that in dsGFP-treated females at 2 DAE (Figure 5B). Supplementation of dsFz2-treated females with the $\mathrm{JH}$ analog methoprene partially rescued $V g$ expression at $1 \mathrm{DAE}$ and $2 \mathrm{DAE}$ $(F=68.6 ; \mathrm{df}=1,5 ; P=0.0001$ for $1 \mathrm{DAE}$ and $F=68.8$; $\mathrm{df}=1,5$; $P=0.0001$ for 2 DAE) (Figures 5C,D), with levels 0.82- and 1.54fold, respectively, of the amount of $\mathrm{Vg}$ in the $\mathrm{dsFz} 2+$ acetone treatment. The application of methoprene to the $\mathrm{dsFz} 2$ treatment partially restored $\mathrm{Vg}$ protein abudance with 0.60 - and 0.51 -fold at $1 \mathrm{DAE}$ and $2 \mathrm{DAE}$, respectively, of the levels of $\mathrm{Vg}$ present in the dsFs2 + acetone treatment (Figures 5E,F).

\section{Frizzled 2 Silencing Has Multiple Effects on C. lividipennis Adult Females}

Dietary dsFz2 treatment led to significant decreases in soluble protein content of ovaries and fat bodies, which were $15 \%$ $(F=9.4 ; \mathrm{df}=1,5 ; P=0.0372)$ and $27 \%$ lower $(F=25.3$; df $=1,5 ; P=0.0073)$ than dsGFP treatment at $2 \mathrm{DAE}$, respectively (Figures 6A,B). RNAi-mediated depletion of $F z 2$ decreased JH III titers $(\downarrow 18 \%: F=22.1 ; \mathrm{df}=1,5 ; P=0.0093)$ and increased ecdysteroid titers $(\uparrow 43 \%: \mathrm{F}=113.5$; $\mathrm{df}=1,5$; $P=0.0004$ ) at $2 \mathrm{DAE}$ (Figures 6C,D). The knockdown of Fz2 led to decreased predation capacity for C. lividipennis female adults $(\downarrow 34 \%: F=25.6$; df $=1,5 ; P=0.0003)$ compared to dsGFP-treated females at 2 DAE (Figure 6E); furthermore, $F z 2$ silencing caused a significant decline $(\downarrow 54 \%: F=18.7$; $\mathrm{df}=1,5 ; P=0.0124)$ in body weight compared to dsGFP at 2 DAE (Figure 6F). 


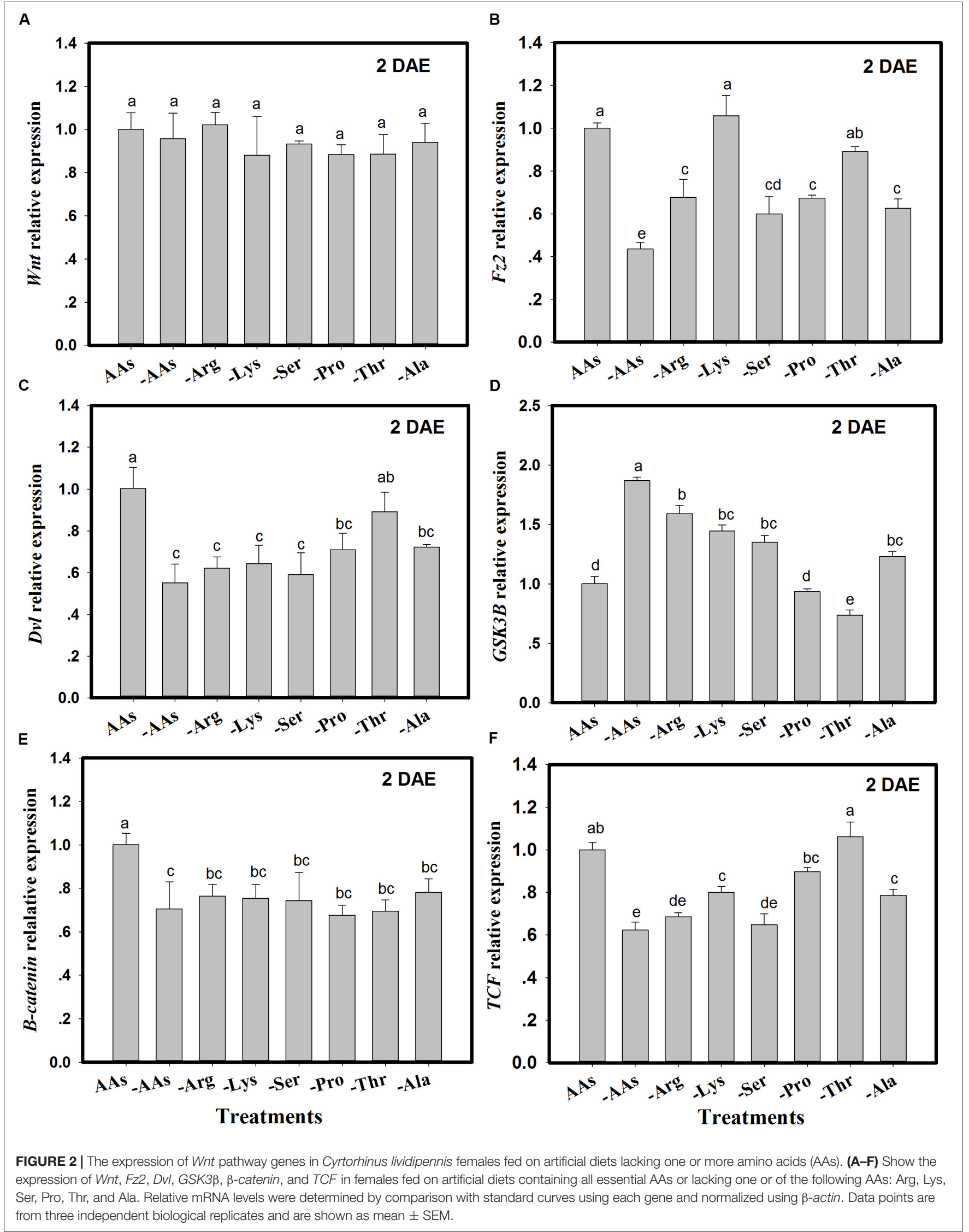



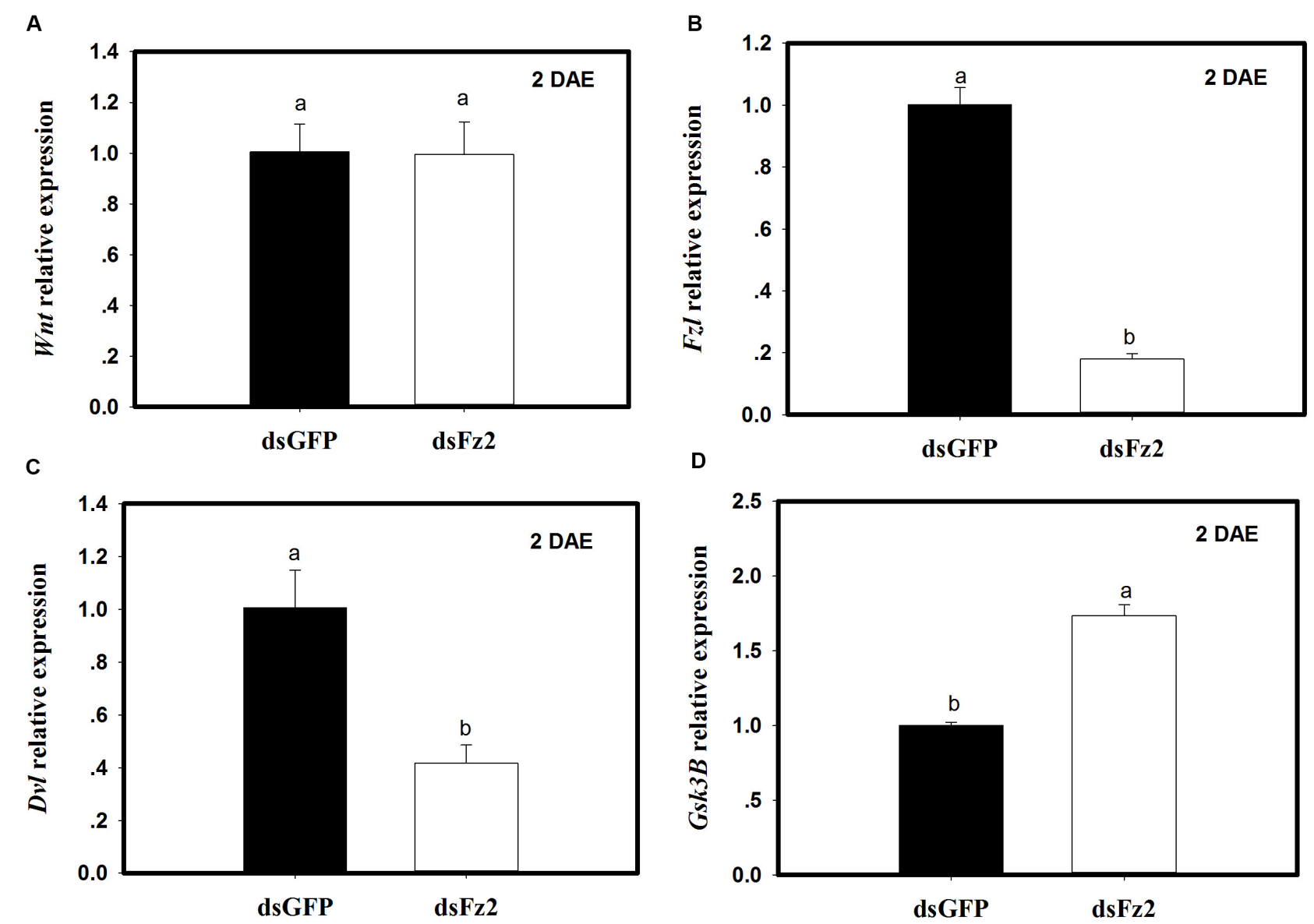

E

F

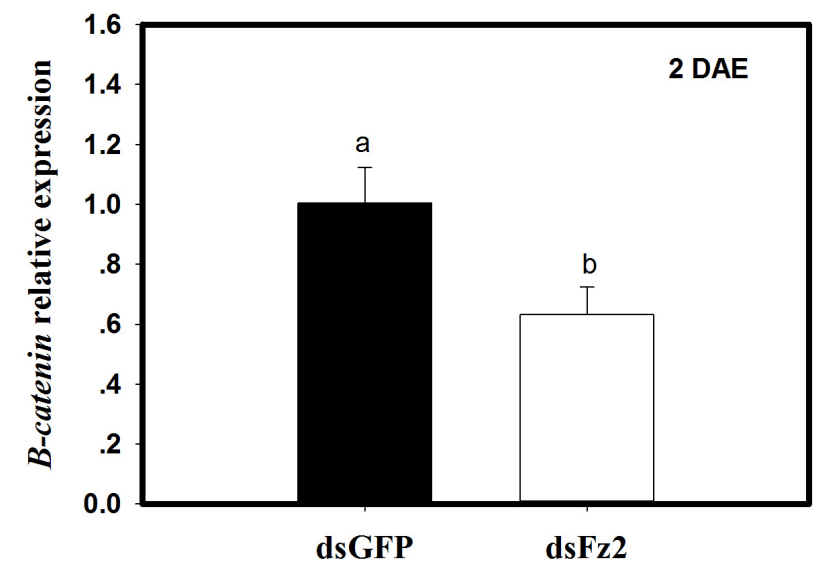

Treatments

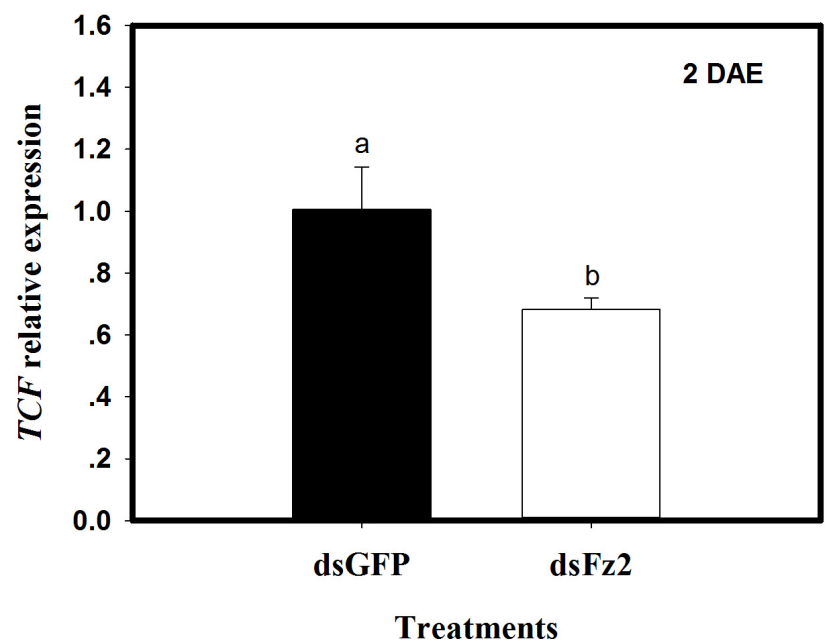

FIGURE 3 | Silencing Frizzled 2 (Fz2) results in reduced expression of selected genes in the Wht signaling pathway. (A-F) Show mean expression levels of Wht, Fz2, DvI, GSK3 $\beta, \beta$-catenin, and TCF, respectively, in dsGFP- and dsFs2-treated Cyrtorhinus lividipennis at 2 days after emergence (DAE). Relative mRNA levels were determined as stated above and normalized with $\beta$-actin. Data points are from three independent biological replicates and represent mean \pm SEM.

\section{Frizzled 2 Silencing Impacts} Reproduction of C. lividipennis Females

Dietary dsFz2, dsTOR, and dsFz2/dsTOR (Figure 7A) resulted in significantly lower numbers of eggs laid as compared to the dsGFP treatment group (dsFz2 $\downarrow 61 \%$; dsTOR $\downarrow 58 \%$; $\mathrm{dsFz} 2 / \mathrm{dsTOR} \downarrow 65 \% ; F=95.7$; df $=3,39 ; P=0.0001)$. RNAimediated depletion of $F z 2$ resulted in a prolonged preoviposition period $(\uparrow 78 \% ; F=12.2 ; \mathrm{df}=1,19 ; P=0.0026)$ (Figure $7 \mathbf{B})$. 
A

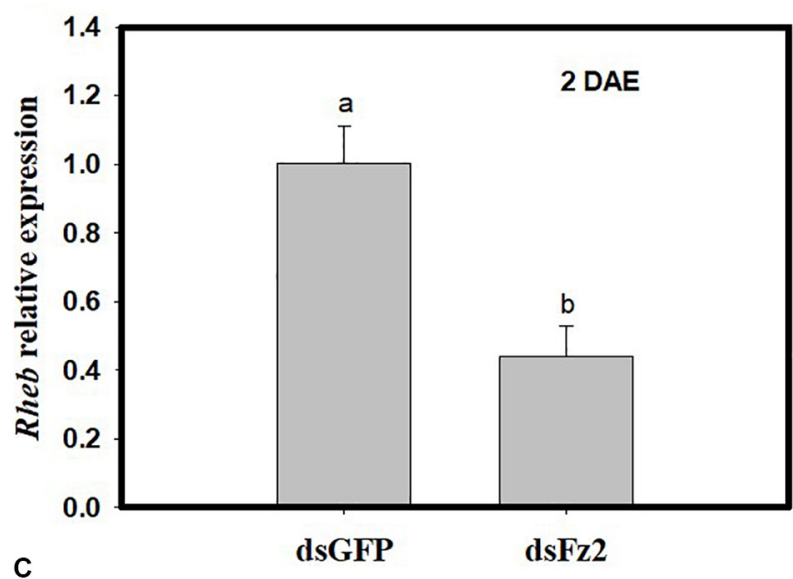

C

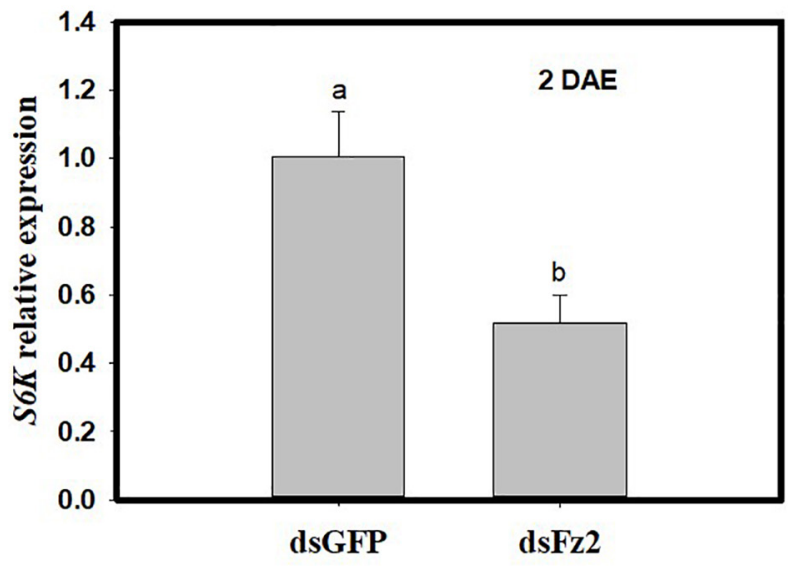

Treatments
B

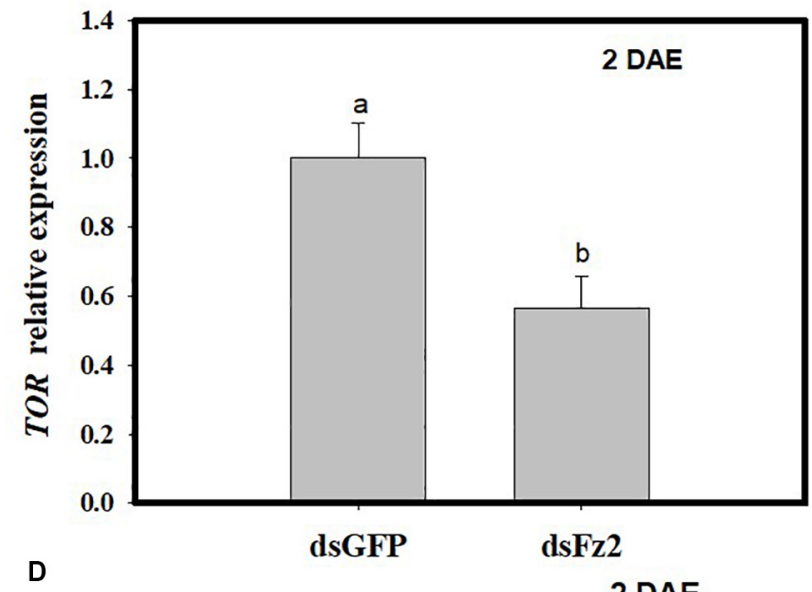

2 DAE

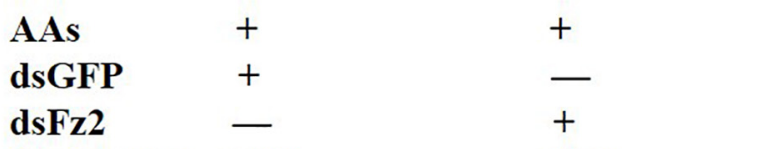

$\begin{array}{lll}\text { Gray value } 1.00 & 0.59\end{array}$

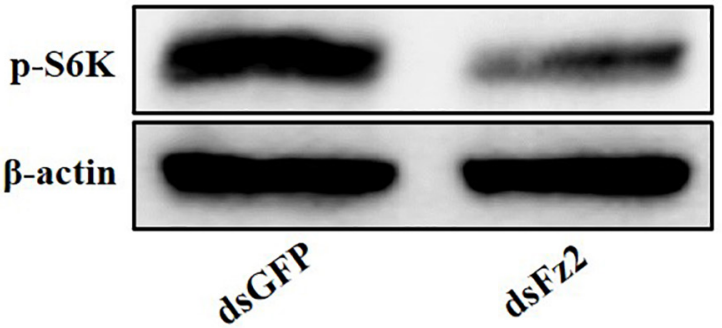

Treatment

FIGURE 4 | Silencing Frizzled 2 (Fz2) inhibits the expression and activity of selected components in the target of rapamycin (TOR) signaling pathway. (A-C) Show the mean expression levels of Rheb, TOR, and S6K at 2 days after emergence (DAE), respectively, in dsGFP- and dsFs2-treated Cyrtorhinus lividipennis. Relative mRNA levels were determined by comparison with standard curves using each gene and normalized using $\beta$-actin. (D) Shows the phosphorylation of S6K in fat body isolated from dsGFP- and dsFz2-treated C. lividipennis at 2 DAE. Phosphorylation was detected by Western blot analysis using phospho-p70-Thr-389 S6K polyclonal antisera; the loading control ( $\beta$-actin) was analyzed using anti- $\beta$-actin antisera. Expression data points are from three independent biological replicates and are presented as the mean \pm SEM.

However, there were no significant differences in dsFz2- and dsGFP-treated females for the oviposition period $(F=1.2 ; \mathrm{df}=1$, 19; $P=0.2837)$ or longevity $(F=0.001 ; \mathrm{df}=1,19 ; P=0.9454)$ (Figures 7C,D). The depletion of $F z 2$ resulted in a significant reduction in oocyte development $(\downarrow 47 \%, F=28.3$; $\mathrm{df}=1$, 19; $P=0.0001$ ) as compared to dsGFP treatment (Figure 7E). Since the number of eggs produced by dsFz2/dsTOR-treated C. lividipennis showed no significant difference from that of dsFz2- or dsTOR-treated females (Figure 7A), the data suggest that $F z 2$ and TOR regulate egg production via a shared pathway.

\section{Frizzled 2 Silencing Inhibits Oocyte Development and Vg Uptake}

There were no obvious external morphological changes in C. lividipennis females after $\mathrm{dsFz} 2$ treatment (data not shown). In the ovaries of the dsGFP-treated control group, every ovariole contained one or two fully developed banana-shaped oocytes at 4 DAE (Figure 8A). However, dsFz2 treatment resulted in undeveloped ovaries and limited oocyte growth (Figure 8E). No fully developed oocytes were observed in dsFz2-treated females at 5 DAE (data not shown). To obtain more details on the phenotype of $F z 2$ silenced females, immunohistochemical (IHC) staining was performed. The results of IHC staining showed that the uptake of vitellin by the oocytes was inhibited when Fz2 was depleted (Figure 8G) as compared to the dsGFP treatment (Figure 8C). We scarcely observed scattered Vg and no patency was spotted in the dsFz2 treatment (Figure 8G).

\section{Frizzled 2 Silencing Inhibits Embryonic Development}

The phenotype of eggs laid by dsFz2-treated females of C. lividipennis was examined at 2, 4, and 6 DAE (Figure 9). Eggs 


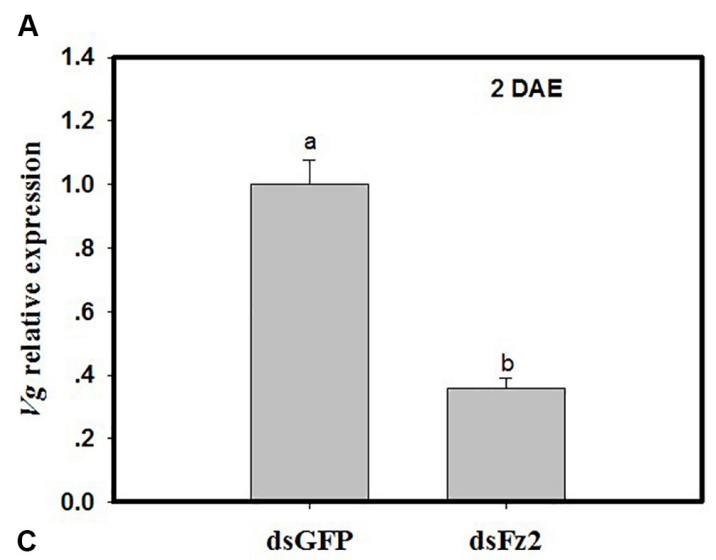

B
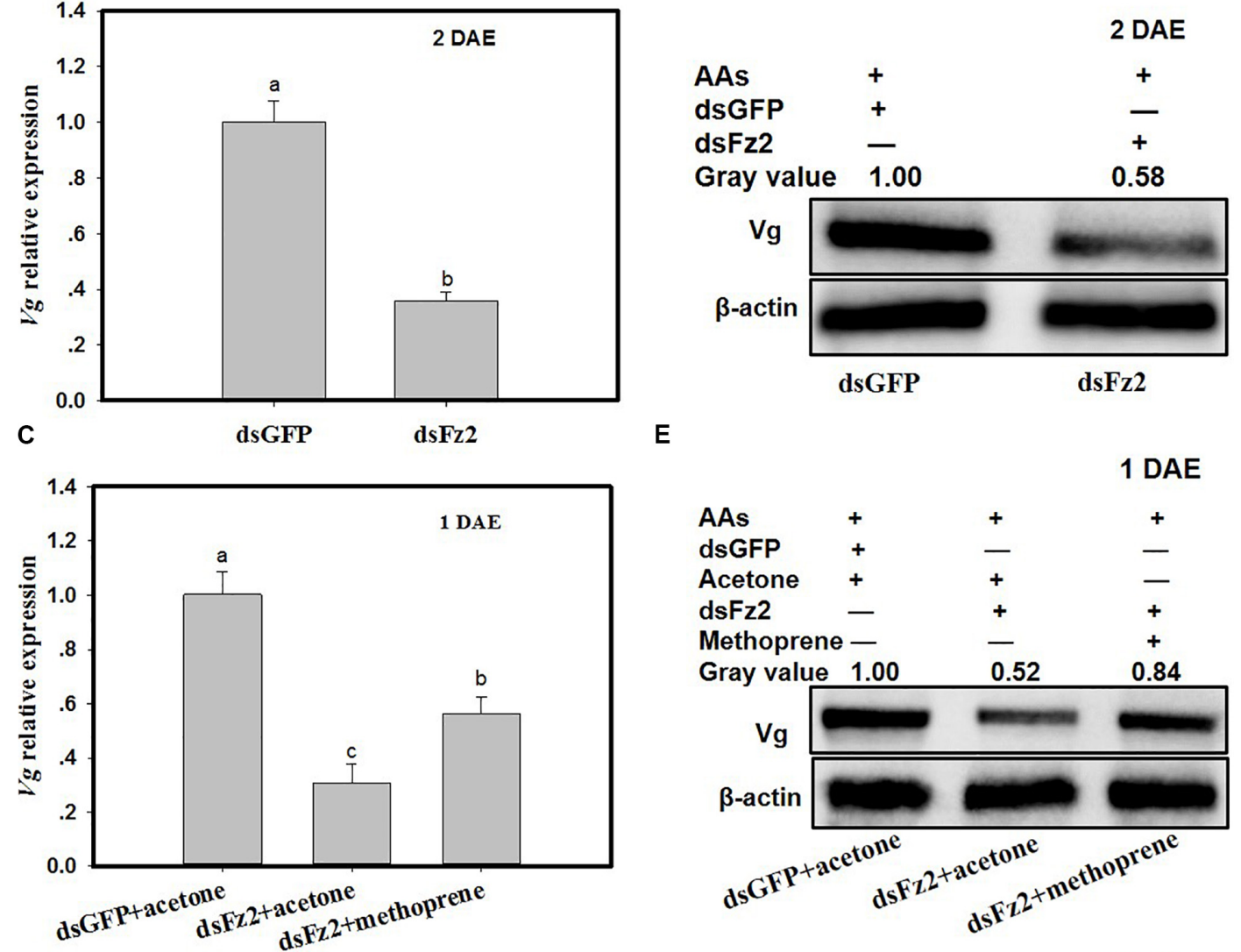

E

D
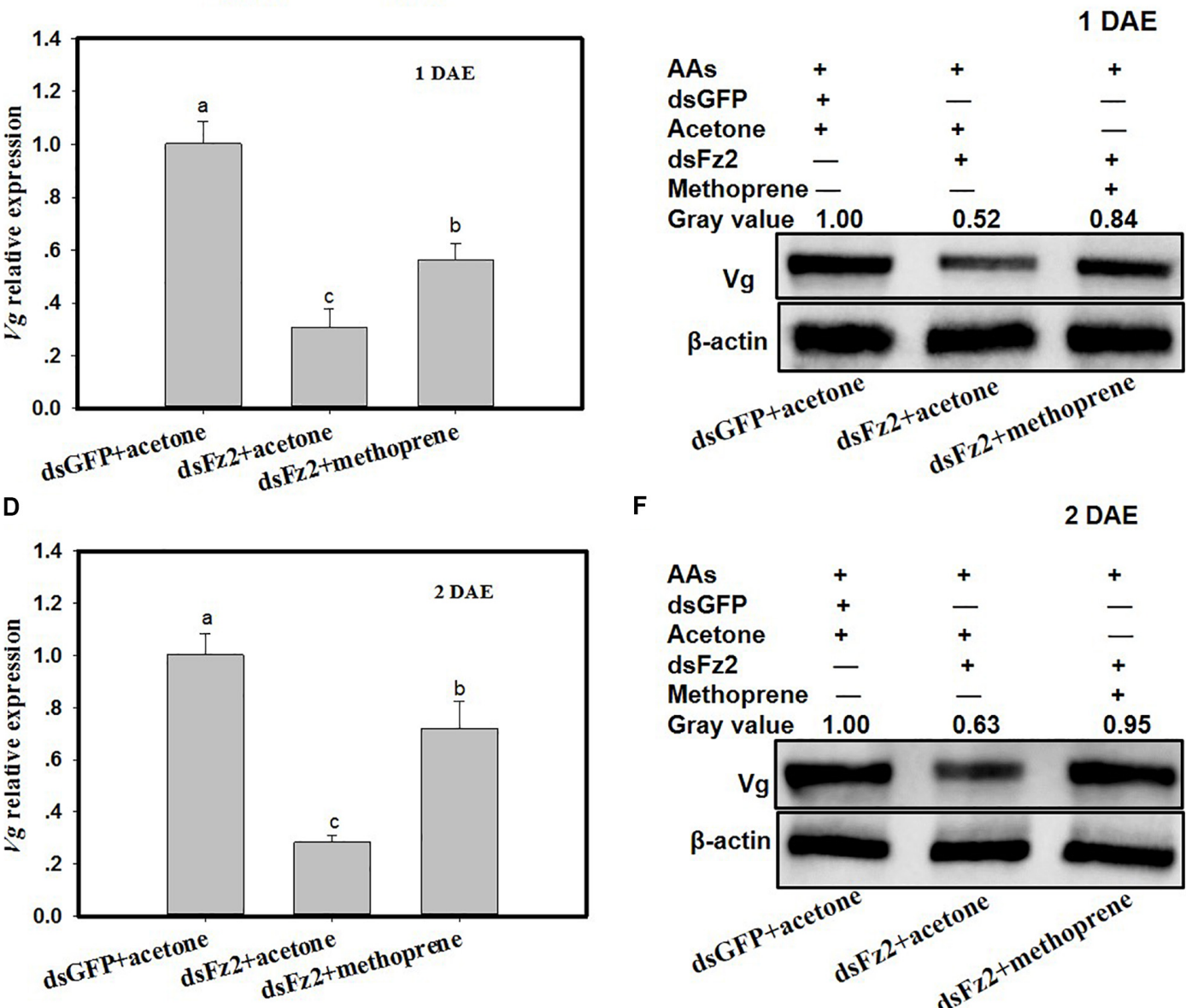

Treatments

$\mathbf{F}$

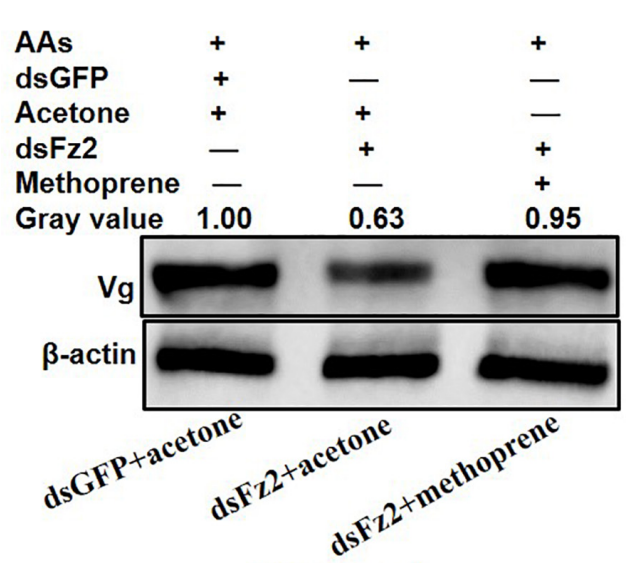

Treatments

FIGURE 5 | Frizzled 2 (Fz2) silencing inhibits the expression and production of Vg in the Cyrtorhinus lividipennis fat body. (A,B) Show the mean Vg expression and $\mathrm{Vg}$ protein levels at 2 days after emergence (DAE) in dsGFP- and dsFz2-treated C. lividipennis as determined by quantitative real-time PCR (qPCR) and Western blot analysis, respectively. (C,D) Show Vg expression at 1 DAE and 2 DAE. (E,F) Show Vg protein production as measured by Western blot analysis with antibody against $\beta$-actin as a loading control at 1 DAE and 2 DAE after methorprene and acetone treatments with new emergence dsGFP-and dsFz2-treated female adult. The relative mRNA levels were determined by comparison with the standard curve of the gene concerned and normalized against the $\beta$-actin gene. $\beta$-actin antibody was used as the loading control. The relative gray values normalized to $\beta$-actin were marked above corresponding bands. Expression data are from three independent biological replicates and are presented as the mean \pm SEM.

laid by dsGFP- and dsFz2-treated females showed no obvious morphological differences at 2 DAE (Figures 9A,D). Eyespots were observed at days 4 and 6 in eggs of dsGFP-treated females
(Figures 9B,C); however, eyespots were absent in the dsFz2treated embryos (Figures 9E,F). DAPI staining confirmed the eyespots in eggs laid by dsGFP-treated females at 4 and 6 DAE 

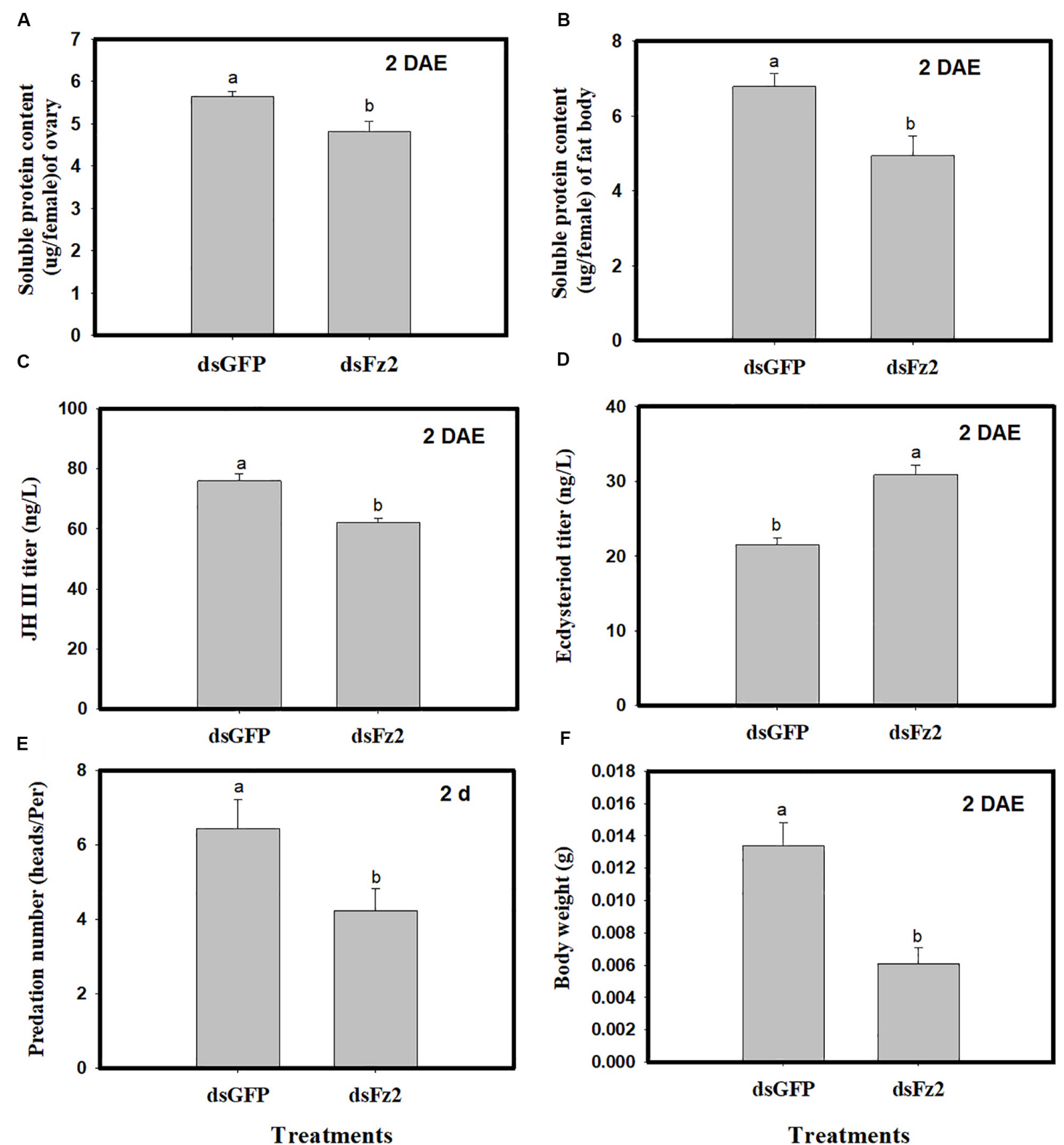

FIGURE 6 | Effect of Frizzled 2 (Fz2) silencing on soluble proteins, JH III and ecdysteroid titers and predation. Cyrtorhinus lividipennis female adults were treated with dsGFP (control) or dsFz2, and data were analyzed 2 days after emergence (DAE). (A,B) Show the mean soluble protein in ovaries and fat bodies, respectively. (C,D) Represent mean JH III and ecdysteroid titers; and (E,F) indicate mean predation number and body weight, respectively. The data shown are from three independent biological replicates and are presented as the mean \pm SEM.

(Figures 9H,I) and the absence of eyespots in dsFz2-treated embryos (Figures 9K,L).

\section{Effects of Frizzled 2 Silencing on Numbers of Offspring, Hatching Rate, Gender Ratio, and Population Growth Index}

Dietary supplementation with dsFz2 led to reduced numbers of offspring ( $F=27.5 ; \mathrm{df}=1,9 ; P=0.0001)$, hatching rates $(F=38.7 ; \mathrm{df}=1,9 ; P=0.0003)$, and PGI values $(F=29.8$; df $=1,9 ; P=0.0001$ ), which were 53, 30, and 34\% lower, respectively, than those in dsGFP-treated females (Table 1). However, no significant difference in gender ratios was detected between dsGFP- and dsFz2-treated females $(F=0.1$; df $=1,9$; $P=0.7651)$.

\section{DISCUSSION}

This study demonstrates the critical role of $F z 2$ in the fertility of the predator $C$. lividipennis. Fz2 activated the Wnt/ $\beta$-catenin 


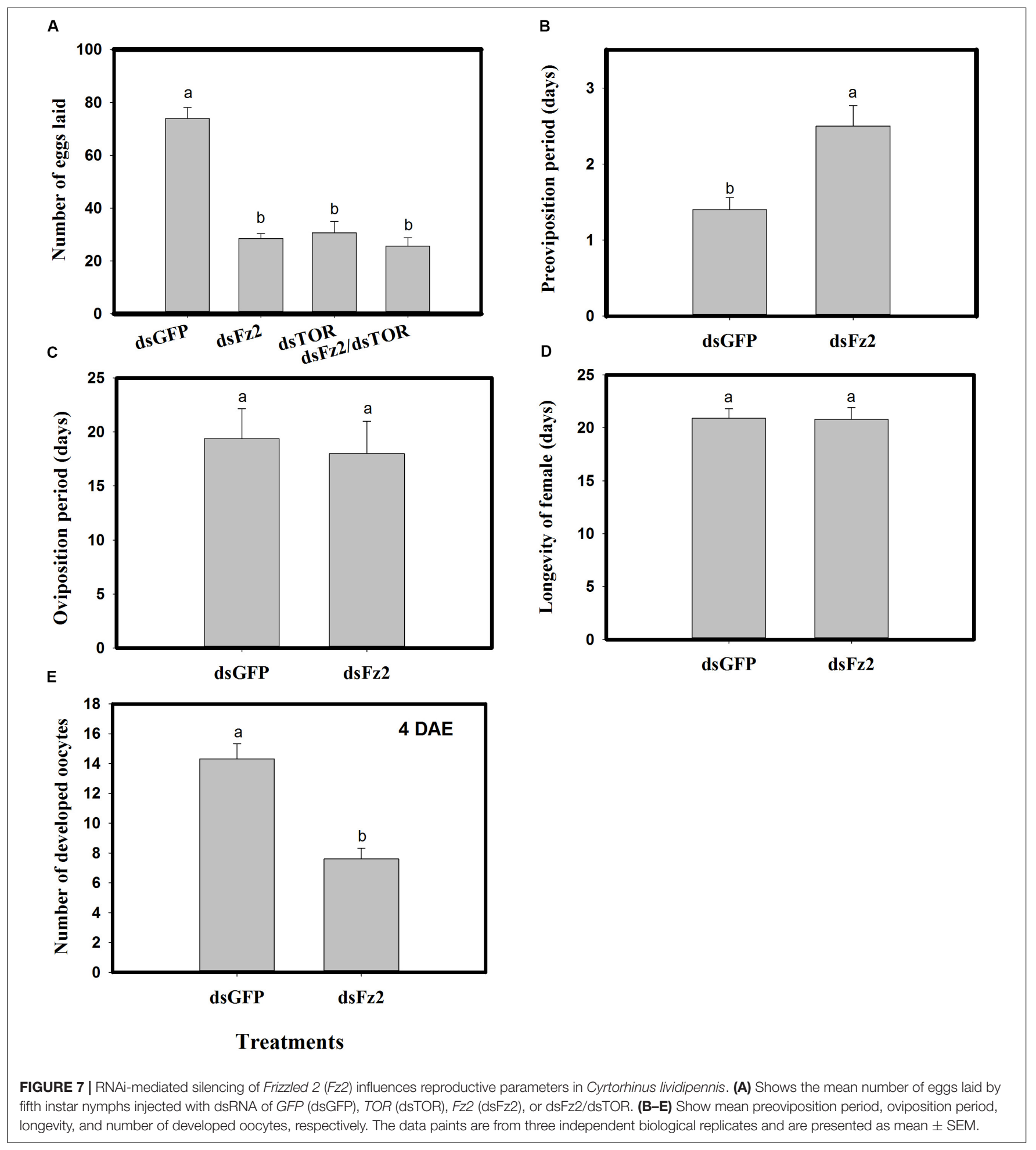

and TOR signaling pathways and modulated embryonic development, oogenesis, and reproduction. Fz2 expression steadily increased from the fifth nymph stage to adults at 2 DAE and was highly expressed in fat bodies. When C. lividipennis was fed on AA-deprived artificial diets, expression of Wnt pathway components was altered, although Wnt expression was not directly impacted (Figure 2). Furthermore, RNAi-mediated depletion of $F z 2$ inhibited the expression of selected genes in the Wnt and TOR signaling pathways (Figures 3, 4).

The conserved TOR pathway detects nutritional signals and mediates S6K phosphorylation, which results in vitellogenesis 


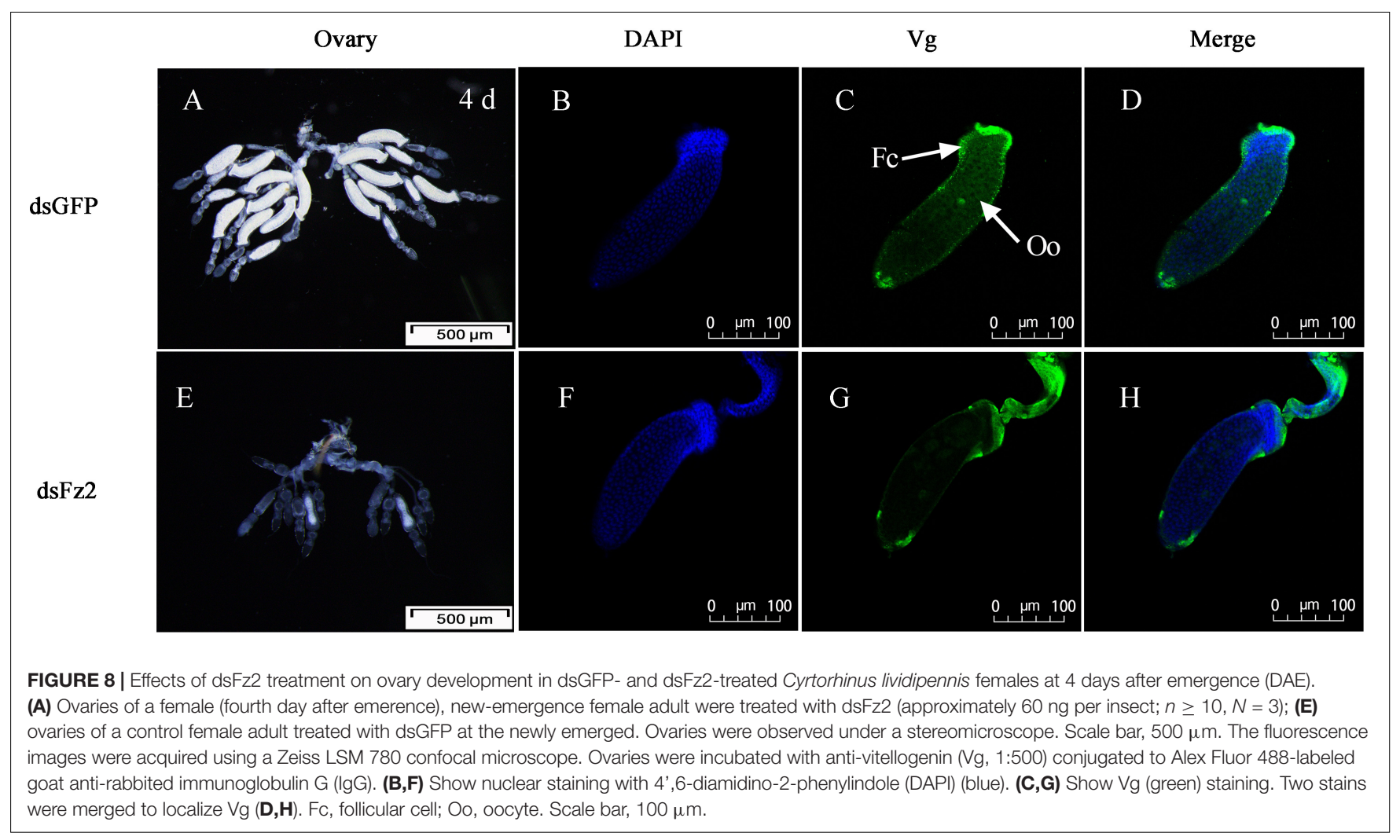

(Attardo et al., 2003; Park et al., 2006). In C. lividipennis, RNAi-mediated depletion of $F z 2$ decreased $V g$ expression, $\mathrm{Vg}$ protein synthesis, and $\mathrm{S} 6 \mathrm{~K}$ phosphorylation, indicating that $F z 2$ was a key component in the TOR signaling pathway. Vitellogenesis is the process of accumulating $\mathrm{Vg}$ and other compounds into developing oocytes (Davey et al., 1994; Sappington and Raikhel, 1998). When oocytes are fully developed, they are coated with chorion and become "eggs" in ovarioles (Ramaswamy et al., 1990). We show that Fz2 silencing inhibited TOR signal transduction and S6K phosphorylation, resulting in reduced Vg protein synthesis and impaired oocyte development.

In insects, a variety of endocrine signals are associated with the development of ovaries (Roy et al., 2018); one example is $\mathrm{JH}$, which prevents premature metamorphosis (Jindra et al., 2013). In the current study, the addition of the JH analog methoprene to dsFz2 treatments rescued both $V g$ expression and $\mathrm{Vg}$ protein synthesis (Figure 5), thus supporting the role of $F z 2$

TABLE 1 | Effects of Frizzled 2 (Fz2) silencing on the number of offspring, hatching rate, gender ratio, and population growth index (PGI).

\begin{tabular}{lcccc}
\hline Treatments & $\begin{array}{c}\text { Number of } \\
\text { offspring }\end{array}$ & $\begin{array}{c}\text { Hatching } \\
\text { rate }\end{array}$ & $\begin{array}{c}\text { Gender } \\
\text { ratio }\end{array}$ & PGI \\
\hline dsGFPo $\times$ controlo" & $230 \pm 46.1 \mathrm{a}$ & $0.78 \pm 0.05 \mathrm{a}$ & $1.14 \pm 0.11 \mathrm{a}$ & $36.7 \pm 5.6 \mathrm{a}$ \\
$\mathrm{dsFz2} \times$ controlo" & $106.2 \pm 25.9 \mathrm{~b}$ & $0.55 \pm 0.07 \mathrm{~b}$ & $1.09 \pm 0.09 \mathrm{a}$ & $24.3 \pm 3.2 \mathrm{~b}$ \\
\hline${ }^{*}$ Means \pm SE of five replicates. Means within columnns followed by different letters \\
are followed by different letters are significantly different at the 5\% level $(P<0.05)$.
\end{tabular}

in the regulation of $C$. lividipennis vitellogenesis. Furthermore, silencing $F z 2$ decreased soluble proteins in ovaries and fat bodyies, JH III titers, and numbers of developed oocytes and eggs laid (Figures 6, 7). In various adult insects, JH stimulates the development of ovaries via gonadotropin (Riddiford, 1994; Wu et al., 2018; Guo et al., 2018), enhances Vg biosythesis (Satyanarayana et al., 1994; Wyatt and Davey, 1996), and functions to modulate the endocrine system (Oberlander et al., 1995; Martin et al., 2001). JH usually facilitates vitellogenesis in oocytes by inducing follicular patency (Sevala and Davey, 1989; Kim et al., 1999; Jing et al., 2018); furthermore, insect fertility is strongly correlated with the number of ovarioles harboring oocytes (Roitberg et al., 2001). In this study, RNAi-mediated depletion of $F z 2$ impacted fecundity by inhibiting ovarioles, oocytes, and embryonic development (Figures 7-9).

Egg production by dsFz2/dsTOR-treated C. lividipennis was not significantly different from egg numbers produced by dsFz2- or dsTOR-treated C. lividipennis, which suggests that Fz2 and TOR regulate egg production via a shared pathway. In several insect species, the regulation of $\mathrm{JH}$ biosynthesis by nutritional signals and the TOR pathway has been established (Tatar et al., 2001; Tu et al., 2005). For example, The TOR pathway in Blattella germanica was proposed to function in $\mathrm{Vg}$ production along with nutritional signals and $\mathrm{JH}$ biosynthesis (Maestro et al., 2009). In vertebrate organisms, Wnt signaling cooperated with mutliple hormone signaling pathways to modulate development (Wang et al., 2007); for example, the Wnt pathway interacted with estrogen to control transcription in osteoblasts (Kouzmenko et al., 2004; Lieder et al., 2010). In 


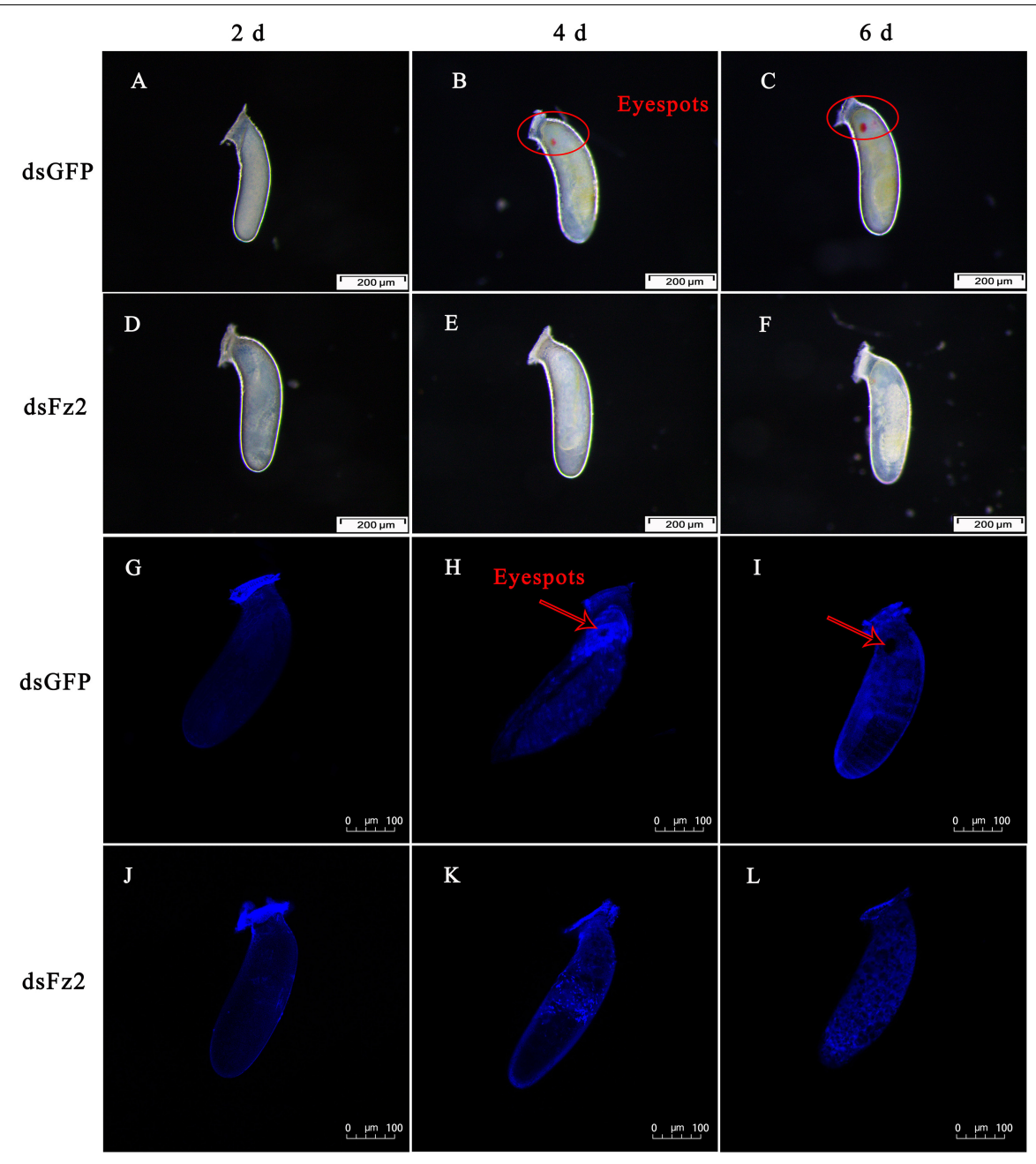

FIGURE 9 | Effects of dsFz2 treatment on eggs and embryonic development at 2, 4, and 6 days after emergence (DAE). (A-C) Show the phenotype of eggs produced by mated Cyrtorhinus lividipennis females treated with dsGFP at 2, 4, and 6 DAE, respectively. (D-F) Show eggs laid by mated C. lividipennis injected with dsFz2 at 2, 4, and 6 DAE, respectively. In (G-I), the nuclear stain 4',6-diamidino-2-phenylindole (DAPI) was used to stain eggs in the dsGFP-treated females at 2, 4, and 6 DAE, respectively. (J-L) Show eggs of dsFz2-treated females stained with DAPI at 2, 4, and 6 DAE, respectively. Fluorescence images were acquired using a Zeiss LSM 780 confocal microscope. Red ovals and arrows indicate the location of eyespots. Scale bar, 100 or $200 \mu \mathrm{m}$.

insects, both Wnt and $\mathrm{JH}$ signaling control many developmental processes (Abdou et al., 2011). In this study, the depletion of $F z 2$ by RNAi led to reduced development of ovaries and embryos and reduced Vg uptake in oocytes. In Drosophila, $\mathrm{Fz}$ was required for tissue polarity in epidermal cells (Gubb, 1993). Furthermore, in A. aegypti, AaFz2 responded to AA signals to stimulate fecundity, and the TOR and Wnt signaling pathways interacted synergistically in vitellogenesis (Weng and Shiao, 2015). The Wnt pathway plays a pivotal role in regulating diapause in Bombyx mori (Lin et al., 2009) and regulates Helicoverpa armigera pupal development (Chen and $\mathrm{Xu}, 2014$ ). Our study establishes a link between Wnt and TOR pathways, which interact synergistically to regulate $C$. lividipennis reproduction in response to AA signals.

In summary, we show that $F z 2$ responds to AA signals that are transduced through the Wnt and TOR pathways and participates in embyonic development, oogensis, and egg production of C. lividipennis females. Furthermore, we demonstrate a cross talk between the Fz2 and TOR pathways in C. lividipennis reproduction. These results provide new insight into large-scale rearing of $C$. lividipennis, and this may ultimately improve the ability to deploy this predator for $\mathrm{BPH}$ control in rice fields.

\section{DATA AVAILABILITY STATEMENT}

The original contributions presented in the study are included in the article/Supplementary Material, further inquiries can be directed to the corresponding author.

\section{AUTHOR CONTRIBUTIONS}

LG designed the research. LJ, SZ, YZ, and QW conducted the experiments. SZ and $\mathrm{YZ}$ performed 
the data analysis. LG wrote the first draft of the manuscript. LG and FL revised the final draft of the manuscript. All authors contributed to the article and approved the submitted version.

\section{FUNDING}

The research was financially supported by the National Key R\&D Program of China (2017YFD0200400); the National Natural Science Foundation of China (31872283); the Natural Science Foundation of Jiangsu Province, China (BK20171283); and the Qinglan Project of Yangzhou University,

\section{REFERENCES}

Abdou, M., Peng, C., Huang, J. H., Zyaan, O., Wang, S., Li, S., et al. (2011). Wnt signaling cross-talks with JH signaling by suppressing Met and Gce expression. PLoS One 6:e26772. doi: 10.1371/journal.pone.002672

Attardo, G. M., Hansen, I. A., Shiao, S. H., and Raikhel, A. S. (2006). Identification of two cationic amino acid transporters required for nutritional signaling during mosquito reproduction. J. Exp. Biol. 209, 3071-3078. doi: 10.1242/jeb. 02349

Attardo, G. M., Higgs, S., Klingler, K. A., Vanlandingham, D. L., and Raikhel, A. S. (2003). RNA interference-mediated knockdown of a GATA factor reveals a link to anautogeny in the mosquito Aedes aegypti. PNAS 100, 13374-13379. doi: 10.1073/pnas.2235649

Base, S. D., Base, T. W., Henje, C., Bae, S. D., Base, T. W., and Cho, H. J. (2002). Effects of temperature and food on the nymphal development and adult longevity of the green mirid bug, Cyrtorhinus lividipennis Reuter (Hemiptera: Miridae) and its egg predation. Korean J. Appl. Entomol. 41, 91-97.

Behura, S. K., Haugen, M., Flannery, E., Sarro, J., Tessier, C. R., Severson, D. W., et al. (2011). Comparative genomic analysis of Drosophila melanogaster and vector mosquito developmental genes. PLoS One 6:e21504. doi: 10.1371/ journal.pone.0021504

Bradford, M. M. (1976). A rapid and sensitive method for the quantitation of microgram quantities of protein utilizing the principle of protein-dye binding. Anal. Biochem. 72, 248-254. doi: 10.1016/003-2697(76)90527-3

Chen, J., Zhang, D., Yao, Q., Zhang, J., Dong, X., Tian, H., et al. (2010). Feedingbased RNA interference of a trehalose phosphate synthase gene in the brown planthopper, Nilaparvata lugens. Insect Mol. Biol. 19, 777-786. doi: 10.1111/j. 1365-2583.2010.01038.x

Chen, W., and $\mathrm{Xu}, \mathrm{W} . \mathrm{H} .(2014)$. Wnt/ $\beta$-catenin signaling regulates Helicoverpa armigera pupal development by up-regulating c-Myc and AP-4. Insect Biochem. Mol. Biol. 53, 44-53. doi: 10.1016/j.ibmb.2014.07.004

Clevers, H. (2006). Wnt/ $\beta$-catenin signaling in development and disease. Cell 127, 469-480. doi: 10.1016/j.cell.2006.10.018

Cornette, R., Gotoh, H., Koshikawa, S., and Miura, T. (2008). Juvenile hormone titers and caste differentiation in the damp-wood termite Hodotermopsis sjostedti (Isoptera, Termospsidae). J. Insect Physiol. 54, 922-930. doi: 10.1016/j. jinsphys.2008.04.017

Curtis, T. Y., Powers, S. J., and Halford, N. G. (2016). Effects of fungicide treatment on free amino acid concentration and acrylamide-forming potential in wheat. J.Agr. Food Chem. 64, 9689-9696. doi: 10.1021/acs.jafc.6b04520

Davey, K. G., Sevala, V. L., Prestwich, G. D., and Jurd, L. L. (1994). “Antagonists and agonists of $\mathrm{JH}$ action on the follicle cells of Locusta migratoria," in Insect Neurochemistry and Neurophysiology, eds A. B. Brokovec and M. J. Loeb (Boca Raton, FL: CRC Press), 285-288.

Fingar, D., and Blenis, J. (2004). Target of rapamycin (TOR): an integrator of nutrient and growth factor signals and coordinator of cell growth and cell cycle progression. Oncogene 23, 3151-3171. doi: 10.1038/sj.onc.1207542

Ge, L. Q., Wang, L. P., Zhao, K. F., Wu, J. C., and Huang, L. J. (2010). Mating pair combinations of insecticide-treated male and female Nilaparvata lugens Stål (Hemiptera: Delphacide) planthoppers influence protein content in the male
Technical System of National Characteristic Vegetable Industry (CARS-24-D-03).

\section{SUPPLEMENTARY MATERIAL}

The Supplementary Material for this article can be found online at: https://www.frontiersin.org/articles/10.3389/fphys. 2020.579233/full\#supplementary-material

TABLE S1 | Comparison of free amino acids in rice (Oryza sativa) and five gramineous species.

TABLE S2 | PCR primers used in this study.

TABLE S3 | Preparation of holomorphic artificial diet for C. lividipennis.

accessory glands (MAGs) and vitellin content in both fat bodies and ovaries of adult females. Pestici. Biochem. Physiol. 98, 278-288. doi: 10.1016/j.pestbp.2010. 06.019

Ge, L. Q., Xia, T., Huang, B., Gu, H. T., Song, Q. S., Yang, G. Q., et al. (2017). PHF7, a novel male gene influences female fecundity and population growth in Nilaparvata lugens Stål (Hemiptera: Delphacidae). Sci. Rep. 7:11611. doi: 10.1038/s415898-11524-2

Ge, L. Q., Zhou, Y. K., Gu, H. T., Wu, Q., Zhou, Z., Zheng, S., et al. (2019). Male selenoprotein F-Like (SPF-L) influences female reproduction and population growth in Nilaparvata lugens (Hemiptera: Delphacidae). Front. Physiol. 10:1196. doi: 10.3389/fphys.2019.01196

Ge, L. Q., Zhou, Z., Sun, K. D., Huang, B., Stanley, D., and Song, Q. S. (2020). The antibiotic jinggangmycin increases brown planthopper (BPH) fecundity by enhancing rice plant sugar concentrations and $\mathrm{BPH}$ insulin-like signaling. Chemosphere 249:126463. doi: 10.1016/j.chemosphere.2020.126463

Giebbultowicz, J., Cymborowski, B., and Delbecque, J. P. (2008). Environmental control of larval behavior and its consequences for ecdysteroid content and pupation in Ephestia kuehniella. Physiol. Entomol. 9, 409-416. doi: 10.1111/ j.1365-3032.1984.tb00782.x

Gordon, M. D., and Nusse, R. (2006). Wnt signaling multiple pathways, multiple receptors, and multiple transcription factors. J. Biolog. Chem. 281, 22429-22433. doi: $10.1074 /$ jbc.R600015200

Gubb, D. (1993). Genes controlling cellular polarity in Drosophila. Dev. Suppl 1993, 269-277. doi: 10.1016/S0070-2153(08)60213-6

Guo, W., Wu, Z., Yang, L., Cai, Z., Zhao, L., and Zhou, S. (2018). Juvenile hormone-dependent kazal-type serine protease inhibitor Greglin safeguards insect vitellogenesis and egg production. FASEB J. 33, 917-927. doi: 10.1096/ fj.201801068R

Hansen, I. A., Attardo, G. M., Park, J. H., Peng, Q., and Raikhel, A. S. (2004). Target of rapamycin-mediated amino acid signaling in mosquito anautogeny. PNAS 101, 10626-10631. doi: 10.1073/pnas.040360101

Hansen, I. A., Attardo, G. M., Roy, S. G., and Raikhel, A. S. (2005). Target of rapamycin-dependent activation of S6 kinase is a central step in the transduction of nutritional signals during egg development in a mosquito. J. Biol. Chem. 280, 20565-20572. doi: 10.1074/jbc.m500712200

He, J. J., Zheng, X. S., Xu, H. X., Yang, Y. J., and Lyu, Z. X. (2014). Successive impacts of different temperatures on the growth, development and reproduction of Cyrtorhinus lividipennis over three generations. Acta Agr. Zhejingensis 26, 117-121.

Jindra, M., Palli, S. R., and Riddiford, L. M. (2013). The juvenile hormone signaling pathway in insect development. Annu. Rev. Entomol. 58, 181-204. doi: 10.1146/ annurev-ento-120811-153700

Jing, Y. P., An, H., Zhang, S., Wang, N., and Zhou, S. (2018). Protein kinase C mediates juvenile hormone-dependent phosphorylation of $\mathrm{Na}+\mathrm{K}+$-ATPase to induce ovarian follicular patency for yolk protein uptake. J. Biol. Chem. 293, 20112-20122. doi: 10.1074/jbc.RA118.005692

Katti, G., Pasalu, I. C., Padmakumari, A. P., Padmavathi, C., Jhansilakshmi, V., Krishnaiah, N. V., et al. (2007). Biological Control of Insect Pests of Rice. Hyderabad. Technical Bulletin No. 22, Directorate of Rice Research. 
Kennerdell, J. R., and Carthew, R. W. (1998). Use of dsRNA-mediated genetic interference to demonstrate that fizzled and fizzled 2 act in the wingless pathway. Cell 95, 1017-1026. doi: 10.1016/S0092-8674(00)81725-0

Kim, Y., Davari, E. D., Sevala, V., and Davey, K. G. (1999). Functional binding of a vertebrate hormone, L-3,5,3'-triiodothyronine (T3), on insect follicle cell membranes. Insect Biochem. Mol. Biol. 29, 943-950. doi: 10.1016/s09651748(99)00070-3

Kouzmenko, A. P., Takeyama, K., Ito, S., Furutani, T., Sawatsubashi, S., Maki, A., et al. (2004). Wnt/beta-catenin and estrogen signaling converge in vivo. J. Biol. Chem. 279, 40255-40258. doi: 10.1074/jbc.C400331200

Lieder, A., Wagner, L., Seefried, L., Ebert, R., Jakob, F., and Ignatius, A. (2010). Estrogen receptor and Wnt signaling interact to regulate early gene expression in response to mechanical strain in osteoblastic cells. Biochem. Biophy. Res. Commun. 394, 755-759. doi: 10.1016/j.bbrc.2010.03.065

Lin, J. L., Lin, P. L., and Gu, S. H. (2009). Phosphorylation of glycogen synthase kinase- $3 \beta$ in relation to diapause processing in the silk worm, Bombyx mori. J. Insect Physiol. 55, 593-598. doi: 10.1016/j.jinsphys.2009.03.007

Livak, K. J., and Schmittgen, T. D. (2001). Analysis of relative gene expression data using real-time quantitative PCR and the 2- $\Delta \Delta$ ct method. Methods 25, 402-408. doi: 10.1006/meth.2001.1262

Loewith, R., and Hall, M. N. (2011). Target of rapamycin (TOR) in nutrient signaling and growth control. Genetics 189, 1177-1201. doi: 10.1534/genetics. 111.133363

Logan, C. Y., and Nusse, R. (2004). Wnt signaling in the immune system: Wnt is spreading its wings. Ann. Rev. Cell. Dev. Biol. 20, 781-810. doi: 10.1038/nri3847

Lu, K., Chen, X., Liu, W. T., and Zhou, Q. (2016). TOR pathway-mediated juvenile hormone synthesis regulates nutrient-dependent female reproduction in Nilaparvata lugens (Stål). Inter. J. Mol. Sci. 17, 438. doi: 10.3390/ijms17040438

Maestro, J. L., Cobo, J., and Belles, X. (2009). Target of rapamycin (TOR) mediates the transduction of nutritional signals into juvenile hormone production. J. Biol. Chem. 284, 5506-5513. doi: 10.1074/jbc.M87042200

Martin, D., Wang, S. F., and And Raikhel, A. S. (2001). The vitellogenin gene of the mosquito Aedes aegypti is a direct target of ecdysteroid receptor. Mol. Cell Endocrinol. 173, 75-86. doi: 10.1016/S0303-7207(00)00413-5

Mikels, A. J., and Nusse, R. (2006). Wnts as ligands: processing, secretion and reception. Oncogene 25, 7461-7468. doi: 10.1038/sj.onc.1210053

Mosimann, C., Hausmann, G., and Basler, K. (2009). (-catenin hits chromatin: regulation of Wnt target gene activation. Nat. Rev. 10, 276-283. doi: 10.1038/ nrm2654

Nusse, R., and Varmus, H. E. (1982). Many tumors induced by the mouse mammary tumor virus contain a provirus integrated in the same region of the host genome. Cell 31, 99-109. doi: 10.1016/0092-8674(82)90409-3

Oberlander, H., Silhacek, D. L., and And Porcheron, P. (1995). Non-steroidal ecdysteroid agonists: tools for the study of hormonal action. Arch. Insect Biochem. Physiol. 28, 209-223. doi: 10.1002/arch.940280303

Park, J. H., Attardo, G. M., Hansen, I. A., and Raikhel, A. S. (2006). GATA factor translation is the final downstream step in the amino acid/target-of-rapamycinmediated vitellogenin gene expression in the anautogenous mosquito Aedes aegypti. J.Biol.Chem. 281, 11167-11176. doi: 10.1074/jbc.M601517200

Ramaswamy, S. B., Mbata, G. N., and Cohen, N. E. (1990). Necessity of juvenile hormone for choriogenesis in the moth, Heliothis virescens (Noctuidae). Invertebr. Reprod. Dev. 17, 27-33. doi: 10.1080/07924259.1990.9672088

Reyes, T. M., and Gabriel, B. P. (1975). The life history and consumption habits of Cyrtorhinus lividipennis Reuter (Hemiptera: Miridae). Philippine Entomol. 3, $79-88$.

Riddiford, L. M. (1994). Cellular and molecular actions of juvenile hormone. I. General considerations and premetamorphic actions. Adv. Insect Physiol. 24, 213-274. doi: 10.1016/S0065-2806(08)60084-3

Rijsewijk, F., Schuermann, M., Wagenaar, E., Parren, P., Weigel, D., and Nusse, R. (1987). The Drosophila homolog of the mouse mammary oncogene int1 is identical to the segment polarity gene wingless. Cell 50, 649-657. doi: 10.1016/0092-867(87)90038-9

Roitberg, B. D., Boivin, G., and Vet, L. E. M. (2001). Fitness, parasitoids, and biological control: an opinion. Can. Entomol. 133, 429-438. doi: 10.4039/ Ent133429-3

Roy, S., Saha, T. T., Zou, Z., and Raikhel, A. S. (2018). Regulatory pathways controlling female insect reproduction. Ann. Rev. Entomol. 63, 489-511. doi: 10.1146/annurev-ento-020117-043258
Sappington, T. W., and Raikhel, A. S. (1998). Molecular characteristics of insect vitellogenins and vitellogenin receptors. Insect Biochem. Mol. Biol. 28, 277-300. doi: 10.1016/s0965-1748(97)00110-0

Satyanarayana, K., Bradfield, J. Y., Bhasharan, G., and Dahm, K. H. (1994). Stimulation of vitellogenin production by methoprene in prepupae and pupae of Manduca sexta. Arch. Insect Biochem. Physiol. 25, 21-37. doi: 10.1002/arch. 940250104

Sen, M., and Ghosh, G. (2008). Transcriptional outcome of Wnt-Frizzled signal transduction in inflammation: evolving concepts. J. Immunol. 181, 4441-4445. doi: 10.4049/jimmunol.181.7.441

Sevala, V. L., and Davey, K. G. (1989). Action of juvenile hormone on the follicle cells of Rhodnius prolixus: evidence for a novel regulatory mechanism involving protein kinase C. Experientia 45, 355-366. doi: 10.1007/2FBF01957476

Shiao, S. H., Whitten, M. M., Zachary, D., Hoffmann, J. A., and Levashina, E. A. (2006). Fz2 and Cdc42 mediate melanization and actin polymerization but are dispensable for Plasmodium killing in the mosquito midgut. PLoS Path. 2:e133. doi: 10.1371/journal.ppat.oo20133

Sigsgaard, L. (2007). Early season natural control of the brown planthopper, Nilaparvata lugens: the contribution and interaction of two spider species and a predatory bug. Bull. Entomol. Res. 97, 533-544. doi: 10.1017/ S0007485307005159

Tang, Q. Y., and Feng, M. G. (2007). DPS Data Processing System: Experimental Design, Statistical Analysis, and Data Mining. Beijing: Science Press.

Tatar, M., Kopelman, A., Epstein, D., Tu, M. P., Yin, C. M., and Garofalo, R. (2001). A mutant Drosophila insulin receptor homolog that extends life-span and impairs neuroendocrine function. Science 292, 107-110. doi: 10.1126/ science. 1057987

Tu, M. P., Yin, C. M., and Tatar, M. (2005). Mutations in insulin signaling pathway alter juvenile hormone synthesis in Drosophila melanogaster. Gen.Comp. Endocrinol. 142, 347-356. doi: 10.1016/j.ygcen.2005.02.009

Vinson, C. R., Conover, S., and Adler, P. N. (1989). A Drosophila tissue polarity locus encodes a protein containing seven potential transmembrane domains. Nature 338, 263-264. doi: 10.1038/338263a0

Wang, G. Y., Zhu, J. L., Zhou, W. W., Liu, S., Khairul, Q. M. D., Ansari, N. A., et al. (2018). Identification and expression analysis of putative chemoreception genes from Cyrtorhinus lividipennis (Hemiptera: Miridae) antennal transcriptome. Sci. Rep. 8:12981. doi: 10.1038/s41598-018-31294-9

Wang, L., Shao, Y. Y., and Ballock, R. T. (2007). Thyroid hormone interacts with the Wnt/(-catenin signaling pathway in the terminal differentiation of growth plate chondrocytes. J. Bone Min. Res. 22, 1988-1995. doi: 10.1359/jbmr.070806

Weng, S. C., and Shiao, S. H. (2015). Frizzled 2 is a key component in the regulation of TOR signaling-mediated egg production in the mosquito Aedes aegypti. Insect Biochem. Mol. Biol. 61, 17-24. doi: 10.1016/j.ibmb.2015.03.010

Wu, Z., Guo, W., Yang, L., He, Q., and Zhou, S. (2018). Juvenile hormone promotes locust fat body cell polyploidization and vitellogenesis by activating the transcription of Cdk6 and E2f1. Insect Bioch. Mol. Biol. 102, 1-10. doi: 10.1016/j.ibmb.2018.09002

Wyatt, G. R., and Davey, K. G. (1996). Cellular and molecular actions of juvenile hormone. II. Roles of juvenile hormone in adult insects. Adv. Insect Physiol. 26, 1-155. doi: 10.1016/S0065-2806(08)60030-2

Yu, X. P., Hu, C., and Heong, K. L. (1996). Effects of various non-rice hosts on the growth, reproduction and predation of mirid bug, Cyrtorhinus lividipennis Reuter. Chin. J. Rice Sci. 10, 220-226.

Zhang, B. X., Huang, H. J., Yu, B., Lou, Y. H., Fan, H. W., and Zhang, C. X. (2015). Bicaudal-C plays a vital role in oogenesis in Nilaparvata lugens (Hemiptera: Delphacidae). J. Insect Physiol. 79, 19-26. doi: 10.1016/j.jinsphys.20 15.006

Conflict of Interest: The authors declare that the research was conducted in the absence of any commercial or financial relationships that could be construed as a potential conflict of interest.

Copyright $\odot 2020 \mathrm{Ge}$, Jiang, Zheng, Zhou, Wu and Liu. This is an open-access article distributed under the terms of the Creative Commons Attribution License (CC BY). The use, distribution or reproduction in other forums is permitted, provided the original author(s) and the copyright owner(s) are credited and that the original publication in this journal is cited, in accordance with accepted academic practice. No use, distribution or reproduction is permitted which does not comply with these terms. 